"2018 Special Issue: Behavioural pharmacology and brain-body signalling processes"

Title: Probiotics in digestive, emotional and pain-related disorders.

Authors: Pablo Roman ${ }^{1,2}$, Raquel Abalo ${ }^{3}$, Eva M. Marco ${ }^{4}$, and Diana Cardona ${ }^{1}$.

\title{
Affiliations:
}

1. Departamento de Enfermería, Fisioterapia y Medicina, Universidad de Almería, La Cañada, 04120 Almería, Spain.

2. Departamento de Enfermería, Universitat Jaume I, Avenida de Vicent Sos Baynat, s/n, 12071 Castellón de la Plana, Castellón, Spain.

3. Área de Farmacología y Nutrición, Departamento de Ciencias Básicas de la Salud, Universidad Rey Juan Carlos (URJC), 28922 Alcorcón, Spain; Unidad Asociada I+D+i del Instituto de Química Médica (IQM), Consejo Superior de Investigaciones Científicas (CSIC), Madrid, Spain.; Unidad Asociada I+D+i del Instituto de Investigación en Ciencias de la Alimentación (CIAL), Consejo Superior de Investigaciones Científicas (CSIC), Madrid, Spain; Grupo de Excelencia Investigadora URJC-Banco de Santander-Grupo multidisciplinar de investigación y tratamiento del dolor (i+DOL), Alcorcón, Spain.

4. Departamento de Fisiología (Fisiología Animal II), Facultad de Biología, Universidad Complutense de Madrid, 28040 Madrid, Spain. 


\begin{abstract}
In the recent years, interest on the relationship between gut microbiota and disease states has grown considerably. Indeed, several strategies have been employed to modify the microbiome through the administration of different diets, by the administration of antibiotics or probiotics, or even by transplants of faeces. In the present manuscript we will specifically focus on the potential application of probiotics, which seem as a safe strategy, in the management of digestive, pain and emotional disorders. Herein, we will present evidence from animal models and human studies, despite the translation to the clinic still deserves further investigation. Microbiome influences gut functions as well as neurological activity by a variety of mechanisms that will also be discussed. The design and performance of larger trials is urgently needed to verify whether these new strategies might be useful not only for the treatment of disorders affecting the gastrointestinal tract but also in the management of emotional and pain disorders not directly related to the gut.
\end{abstract}

Keywords: Gut microbiota, probiotics, gastrointestinal disorders, pain, emotion, animal models, human studies. 


\section{THE MICROBIOTA-GUT-BRAIN AXIS}

The gastrointestinal (GI) tract has been described to be home to more than 100 trillion microscopic bacteria $\left(10^{14}\right.$ or $100,000,000,000,000$ cells) and to host more than $70 \%$ of all bodily flora (Vyas and Ranganathan, 2012). The collection of microorganisms colonizing the Gl tract is termed the "gut microbiota" (Bäckhed et al., 2005; Neish, 2009), and is mainly comprised of bacteria (Balzola et al., 2010; Guarner, 2005). Frequently, the importance of gut microbiota has been related to the extended belief that bacteria residing in the human body outnumber human cells by a factor of 10 or more (10:1 ratio); however, a recent research has updated this ratio to closer to $1: 1$ although such a change in numbers should not change the importance of hostmicrobiota interactions (Sender et al., 2016).

The gut is colonized by bacteria from birth, and rapidly reaches concentrations up to $10^{12}$ organisms per gram of luminal contents in the colon (Ohland and Jobin, 2015). Composition of microbiota in the infant depends on different factors, like the type of delivery (vaginal or cesarean), diet (breast milk or formula), or exposure to antibiotics. It is worth mentioning that the gut microbiome contributes to the early programming of epithelial barrier function, angiogenesis, and innate and host immune function (Rodríguez-Fandiño et al., 2010), and evidences from experimental and clinical studies give support to the fact that alterations in the pattern of GI colonization have long-term consequences on immune function. After weaning, microbiome composition changes and by 2 years of age it is similar to that of adults (Salazar et al., 2014). The adult microbiome includes approximately 30 species of Bifidobacterium, 52 species of Lactobacillus, and others, such as Streptococcus and Enterococcus (Wallace et al., 2011). In each region of the gut different microorganisms are found. Thus, grampositive facultative anaerobic bacteria predominate in the proximal small intestine and gram-negative anaerobes in its distal part, whereas in the colon, obligate anaerobes outnumber facultative anaerobes. The gut microbiota produces many metabolic substances, that depend on each individual's microbiome and are critically affected by the individual's diet (Blaut and Clavel, 2007); microbiome-released metabolites may include several vitamins (folate, biotin), short chain fatty acids (propionate, butyrate, acetate) and neuroactive metabolites (serotonin, gamma-butyric acid), among others (Sharon et al., 2014). 
The gut microbiota has been described to exert a profound influence on brain physiology and behaviour (Borre et al., 2014; Carabotti et al., 2015; Cryan and Dinan, 2012; Dinan et al., 2014) through a variety of mechanisms (Chichlowski and Rudolph, 2015). Locally, bacterial products promote myoelectric activity, activate the enteric nervous system (ENS), and stimulate primary afferent nerves (Al-Nedawi et al., 2015; Husebye et al., 1994). Furthermore, circulating bacterial metabolites seem to mediate changes in behaviour (Chichlowski and Rudolph, 2015). But, at the same time, microbiome can also be affected by stress exposure, thus suggesting a bidirectional communication at the brain-gut axis.

Despite intestinal microbiome is considerably stable over time and quite resistant to transient aggression, several GI pathologies have been related to changes in the stability, diversity, composition, and/or metabolism of gut bacteria; this kind of change in the microbiome is known as dysbiosis (Chassard et al., 2012; Mättö et al., 2005; Rajilić-Stojanović et al., 2011). Interestingly, maintenance and restoration of a suitable intestinal microbiota may prevent the development of various diseases, such as allergies, obesity and GI diseases, among others (Martin and Kochhar, 2015). Actually, gut microbiota has arisen as a remarkable symbiotic partner critical for the maintenance of good health (Fond et al., 2015).

During the last decades, interest on the relationship between gut microbiota and disease states has grown considerably. Microbiota has become the focal point of research in relation to several pathological conditions including digestive diseases, emotional and pain-related disorders (Mayer et al., 2015). Indeed, several strategies have been developed to change, both qualitative and/or quantitatively, the microbiome; mainly, the reduction of gut microbiota by the administration of antibiotics, and its enhancement by the administration of probiotics, or even by faecal transplants (Martin \& Kochhar, 2015; Fond et al., 2015). Herein, among the several strategies available, we will focus on the use of probiotics, in both human and animal models, to modify gut microbiota.

\section{PROBIOTICS}

Probiotics are defined by the Food and Agriculture Organization (FAO) and the International Scientific Association for Probiotics and Prebiotics as "live 
microorganisms that, when administered in adequate amounts, confer a health benefit on the host" (Hill et al., 2014). Historically, the concept of probiotics began around 1900 by the Nobel laureate Elie Metchnikoff, who discovered that the consumption of live bacteria (Lactobacillus bulgaricus) in yogurt or fermented milk improved the biological features of the GI tract (Mackowiak, 2013).

Most commonly used probiotics are lactic acid bacteria, namely from the genera Lactobacillus and Bifidobacterium, but also yeasts such as Saccharomyces boulardii. These species are non-pathogenic and can resist the harsh luminal environment of the GI tract (Bezkorovainy, 2001). Probiotic consumption is reported to exert a myriad of positive effects including: enhanced immune response, balancing the colonic microbiota, vaccine adjuvant effects, reduction of faecal enzymes implicated in cancer initiation, treatment of diarrhoea associated with travelling and antibiotic therapy, control of rotavirus and Clostridium difficile-induced colitis and prevention of ulcers related to Helicobacter pylori (Kaur, Chopra, \& Saini, 2002; Khoder et al, 2016) and even, some probiotics have been described as protective against heavy metal exposure (Ojekunle et al., 2017). Beneficial effects of probiotics are mediated by different mechanisms including competition against pathogenic bacteria in their binding to the intestinal epithelial cells, enhancement of intestinal epithelial barrier function, inhibition of the growth of pathogens by secreting antimicrobial peptides, and/or enhancement of serum IgA production, among others (reviewed in Hardy, Harris, Lyon, Beal, \& Foey, 2013; Upadhyay \& Moudgal, 2012).

To guarantee probiotics survival, microencapsulated or coated probiotic strains are sometimes required (Haghshenas et al., 2015; Kailasapathy, 2002; Nami et al., 2017). Remarkably, a newer generation of probiotics is based on their capacity to form biofilms and on the advances of these probiotics encapsulation techniques (Salas-Jara et al., 2016). Occasionally, non-living probiotic strains, known as "para-probiotics" or "ghost probiotics", have also been employed (Adams, 2010; Taverniti and Guglielmetti, 2011). Actually, these non-viable probiotics, resulting from exposure to high temperatures or irradiation, or some probiotic fractions, such as DNA, have been shown to induce immune system stimulation against vancomycin-resistant enterococci (Sakai et al., 2006), have been reported to enhance TNF- $\alpha$ and IL-6 production (Marin et al., 1997), to protect immune-deficient mice against Candida albicans (Wagner et 
al., 2000), to improve the anti-inflammatory response in rats with experimentallyinduced colitis (Rachmilewitz et al., 2004) and to exert anti-proliferative and proapoptotic effects on cancer cells (Orlando et al., 2012).

Prebiotics are non-digestible foods that stimulate the growth and/or activity of bacteria in the GI. Some prebiotics, such as fructo-oligosacharides and galactooligosaccharides, are anaerobically fermented into short-chain fatty acids (SCFAs) (reviewed in Hardy et al., 2013). Accordingly, some recent studies have provided further evidence for prebiotics to affect anxiety, learning and memory although data from human studies are still limited (Burokas et al., 2017; Kao et al., 2016).

Alternative designs for using probiotics are being explored and have been sometimes gathered under the term "pharmabiotics". Pharmabiotics encompasses a broader set of substances, including live and dead microbes, microbial components, and microbe-produced substances (Patterson et al., 2014; Shanahan and Collins, 2010). Moreover, some genetically modified probiotic strains have been designed to be used as vectors for targeted delivery of anti-inflammatory cytokines, vaccines and anti-pathogenic molecules, and have been also refereed as "immunobiotics" (Shigemori and Shimosato, 2017).

Herein, in the present review we will present and discuss the most remarkable data from animal studies and clinical trials that have analysed the effects of probiotics on digestive disorders, emotional and pain-related illnesses.

\section{APPLICATION OF PROBIOTICS IN THE MANAGEMENT OF DIGESTIVE DISORDERS}

The list for $\mathrm{Gl}$ disorders that may be responsive to probiotics is huge (see (Khoder et al., 2016) and references provided therein). The use of probiotics as supplements or alternatives to oral antibiotic therapy in the treatment of GI infectious diseases [i.e., those produced by $H$. pylori, Salmonella or Clostridium difficile, see (Salas-Jara et al., 2016)] is very interesting because they may restore the normal microflora, compete with the pathogenic resistant bacteria and help patients to recover. Probiotics may avoid the use of antimicrobials or reduce the secondary effects associated to their use, such as antibiotic resistance or the negative effects on the health of the patients (Salas-Jara et al., 2016). In a recent study, it was shown that probiotics may reduce infection complications in the critically ill patients and may contribute to earlier 
recovery of gut function, although mortality was not proved to be reduced (Koekkoek and van Zanten, 2017). Curiously, the gram-negative probiotic Escherichia coli (Nissle 1917) was even more effective than gram-positive probiotics (Lactobacilli spp.) at enhancing protective immunity against rotavirus in the gnotobiotic piglet model (Kandasamy et al., 2017).

Focusing now on chronic digestive disorders, these may be divided into two main categories: organic and functional disorders. Organic disorders are those in which alterations of the gut wall structure are patent and clearly related to the disorder. In this category, all kinds of inflammatory-based alterations may be included: gastritis, gastric ulcer, gastric or colorectal cancer, inflammatory bowel disease (IBD), including ulcerative colitis and Crohn's disease, microscopic colitis, celiac disease... In contrast, the term "functional", used for functional GI diseases (FGID), including both functional dyspepsia and irritable bowel syndrome (IBS), indicates that structural or biochemical abnormalities that could explain the symptoms are not evident, based on routine clinical evaluations (Mearin et al., 2016; Tack and Drossman, 2017).

Whereas in organic diseases pain may be present, probably as a consequence of the inflammatory condition itself, in FGID pain is present but its aetiology is not so clear: it may be related to motility alterations and/or to micro- or low-grade inflammation [i.e., mastocytosis, that could be treated with anti-histamine drugs: (Fabisiak et al., 2017)] that only recently is being considered [see for example (Holtmann et al., 2016) for a recent review on IBS pathophysiology]. First, we will provide some recent examples of studies about probiotics potential to treat three main organic disorders: gastric ulcer (and infection by $H$. pylori); IBD; GI cancer. Thereafter, we will illustrate the use of probiotics to treat FGID, and, particularly, pain associated to IBS.

\subsection{INFLAMMATORY CONDITIONS IN THE GASTROINTESTINAL TRACT}

\subsubsection{Evidence from in vitro studies}

Many recent in vitro studies have shown that probiotics may exert interesting activities leading to a reduced inflammation. For example, regarding $H$. pylori infection and consequent gastric inflammation, Streptococcus thermophilus CRL1190 strain reduced $H$. pylori adhesion and attenuated inflammatory response in AGS gastric epithelial cell line. Also, Lactobacillus paracasei strain 06TCa19 increased IL-8 and 
RANTES expression in AGS and MKN45 cells, decreased NF- $\kappa \beta$, p38 MAPK signaling, lactic acid release and CagA virulence protein of $H$. pylori (Takeda et al., 2017). Similarly, the commensal Bacteroides fragilis was shown to enhance the phagocytic functions of macrophages, polarizing them to an M1 phenotype, which highlights the relationship between this bacterium and the innate immune system (Deng et al., 2016). Probiotics are also known to dampen the Th1 response triggered by H. pylori, adherence to the gastric epithelium and secretion of bacterial adhesins and bacteriocidal metabolites (Boltin, 2016).

\subsubsection{Evidence from animal models}

Different animal models have been used to test the role of different types of probiotics in vivo. For example, Lactobacillus fermentum Suo (LF-Suo) inhibited, in a dose-dependent manner, $\mathrm{HCl}$ /ethanol induced gastric injury in mice and the mechanisms involved improvements in mucosal barrier, antioxidant activities, reduction of serum cytokines (IL-6, IL-12, TNF- $\alpha$, IFN- $\gamma$ ), increase in serum motilin, substantia P (SP), endothelin, somatostatin and vasoactive intestinal peptide (VIP), and the normalization of several gastric proteins gene expression (Suo et al., 2016). Also in mice models of gastric ulcers induced by alcohol, restraint cold stress and pyloric ligation, Clostridium butyricum exerted antioxidative and anti-inflammatory effects leading to significantly reduced gastric mucosal injury (Wang et al., 2015a).

In the IBD field, one recent work has shown that iron-responsive Streptococcus thermophilus strain was able to ameliorate colitis induced by dextran sodium sulphate (DSS) in mice. This has been suggested as an alternative to conventional probiotics, which in the iron-rich environment of the colon of IBD patients (due to bleeding and oral iron supplements) would not be as effective. The mechanism involved maintenance of mucosal barrier function and reduced bacterial translocation, thereby reducing immune stimulation and associated inflammation, leading to mucosal healing, as well as to reduced GI bleeding and weight loss (Bailey et al., 2017). Interestingly, using the same model, the beneficial actions of Escherichia coli (Nissle 1917) were potentiated when it was combined with iron supplementation in the form of ferrous sulphate (which is currently used in the clinics to supplement IBD patients), but not of other iron supplements (Constante et al., 2017). Also, in another recent report, Lactobacillus casei 01 was used alone and/or combined with oligofructose- 
enriched inulin in a trinitrobenzenesulfonic acid (TNBS)-induced rat model of colitis. This combination of the probiotic and the prebiotic (oligofructose-enriched inuline) was also tested after its encapsulation in chitosan-Ca-alginate microparticles, which showed the best anti-inflammatory effects (Ivanovska et al., 2017). Thus, even though in vitro studies show that probiotics on their own may exert beneficial effects in inflammatory conditions, a currently hot line of research in preclinical studies is to optimize their in vivo effects, mainly through the combination (after encapsulation or not) with other compounds (prebiotics, nutrients, nutraceuticals...).

\subsubsection{Evidence from clinical studies}

In clinical studies, probiotics may have a significant protective effect in several inflammatory conditions of the gut, although evidences are not available for all conditions. For example, it has recently been shown that probiotics may decrease the incidence of acid-suppressing drugs-associated infections, especially in the elderly (Fisher and Fisher, 2017). In both children and adults, either Asians or not, a recent meta-analysis showed that the addition of probiotics improved $H$. pylori eradication rates, associated to immune system modulation, and, very interesting, probiotics improved medication tolerance and patient compliance with lower levels of nausea, vomiting, diarrhea and epigastric pain (Lau et al., 2016). In a recent review about treatment of gastric ulcer, it was concluded that some probiotics may increase the efficacy and tolerability of the triple therapy, although data related to quadruple concomitant therapy are not definite yet (Gisbert, 2016). Furthermore, it is not clear yet the specific probiotic/s, antibiotic/s and patient factors that might predict benefit from probiotic supplementation in the treatment of gastric ulcer and $H$. pylori infection (Boltin, 2016).

Similarly, in the IBD field, a very recent meta-analysis considering a total of 22 randomized clinical trials, showed that VSL\#3, a mixture of 8 probiotic bacteria strains, may be effective in inducing remission in active ulcerative colitis, and that probiotics may be as effective as 5 -aminosalicylates (5-ASAs) in preventing relapse of quiescent ulcerative colitis. However, the efficacy of probiotics in Crohn's disease remains uncertain, and more evidence from randomized control trials is required (Derwa et al., 2017). Similar results were obtained by another research group (Ganji-Arjenaki and Rafieian-Kopaei, 2017). 


\subsection{GASTROINTESTINAL CANCERS}

Regarding GI neoplasias, several recent in vitro studies have shown that probiotics may exert anti-proliferative and pro-apoptotic effects on cancer cells, although the mechanism involved has not been completely elucidated (Haghshenas et al., 2014; Orlando et al., 2012). In in vitro studies using gastric cancer cell lines, Lactobacillus reuteri down regulated urokinase plasminogen activator/urokinase plasminogen activator receptor gene expression (Rasouli et al., 2017). Also in gastric cancer cell lines and xenograft models, ferrichrome (a siderophore) from Lactobacillus casei ATCC334 induced apoptosis (Ijiri et al., 2017). Lactobacillus salivarius Ren in rats and Clostridium butyricum and Bacillus subtilis in mice were capable of inhibiting dysbiosis and suppressing colon carcinogenesis (Chen et al., 2015; Zhang et al., 2015).

Probiotics may also improve small intestinal bacterial overgrowth, as shown in a Chinese cohort treated with Bifidobacterium triple viable capsule. In this study, small intestinal bacterial overgrowth was related to Gl cancer (gastric and colorectal) and concomitant GI cancer-related symptoms, which were alleviated by the probiotic (Liang et al., 2016). In addition, probiotics can prevent the toxic effects (diarrhea) of chemotherapy and radiotherapy in cancer patients (Chitapanarux et al., 2010; Osterlund et al., 2007). Once again, restoration of normal microflora may play a key role in these effects.

\subsection{FUNCTIONAL GASTROINTESTINAL DISORDERS AND VISCERAL PAIN}

Despite FGID are not categorized as organic diseases, and thus not considered as inflammatory conditions, some subtle (low-grade) inflammation has been observed in both IBS and FD (Camilleri et al., 2012; Holtmann et al., 2016; Lee et al., 2017; Ohman and Simrén, 2010). Actually, this subtle inflammation may participate in the development of symptoms, including pain. In some patients, FGID may have a genetic basis (Beyder et al., 2014; Oshima et al., 2010; Saito et al., 2009). However, other factors have been involved in the development of FGID such as early life events and stress, autoimmune disorders and atopy, infections, disordered mucosal immune activation, and the gut microbiome (Holtmann et al., 2016; Talley et al., 2015).

Whether gut dysbiosis in IBS is a cause or a consequence of the disease remains unclear (Theodorou et al., 2014), but physiologic effects of altered microbiota include bile salt de-conjugation changes leading to changes in stool volume and consistency, as 
well as bacterial fermentation changes resulting in alterations in the gas volume and/or composition, which may underlie the motility alterations typically encountered in this disease (Quigley, 2013, 2017). Motility alterations may facilitate the occurrence of pain.

However, the intestinal microbiota secretes factors that may alter mucosal permeability, activate different types of immune cells and responses, and induce the release of cytokines. These alter visceral pain responses. Interestingly, visceral pain is reduced in germ free mice and is also reduced after administration of antibiotics for 2 weeks in mice (Aguilera et al., 2015). Changes in secretory immunoglobulin A (IgA), toll-like receptors (TLR) as well as in cannabinoid and mu opioid receptors were shown to be involved in the effect of antibiotics (Aguilera et al., 2015). Thus, some of the effects of the microbiota on visceral pain responses are mediated via microbiotaneuroimmune interactions. Changes in mucosal permeability, mucosal immune system composition and the microbiome populations have been described in humans with IBS, further suggesting that microbiota-neuroimmune interactions are key in some visceral pain syndromes (Hughes et al., 2013). Despite the lack of identification of a specific microbial group characteristic for IBS dysbiosis the alterations generally reported concern the Bifidobacterium and Clostridium coccoides-E. rectal subgroup.

Importantly, in addition to gut dysbiosis, visceral pain and psychiatric comorbidity are common features in FGID, including IBS (Mayer, 2011). The origin of visceral hypersensitivity in IBS can be central and/or peripheral (Barbara et al., 2011). Thus, increased neuron excitability has been reported at several levels of the brain-gut axis, i.e., the ENS, spinal cord and supraspinal sites (Feng et al., 2012). At the supraspinal sites, interactions with emotional or stressful influences can modulate the visceral sensitivity resulting in increased pain perception (Hertig et al., 2007). These interactions will be discussed further in this review.

Increased neuron excitability in IBS, in the absence of major inflammation, may be related to the underlying aetiology. For example, IBS may develop after an episode of gastroenteritis and symptoms may still be observed in $10 \%$ of patients up to 10 years after the infectious event. Prospective studies have determined that $3-36 \%$ of enteric infections lead to persistent new IBS symptoms (Spiller and Garsed, 2009), and the following factors seem to be key for their occurrence: gender (female); severe 
symptoms during the infection; infected by Salmonella (as opposed to Escherichia coli); and higher anxiety, depression and somatization baseline scores (Schwille-Kiuntke et al., 2011). Prior infection might trigger subtle local inflammation and persistent neuronal hypersensitization.

On the other hand, during the early neonatal period, there is a critical window at which the microbial colonization of the Gl tract influences the development of both the peripheral and central nervous system. Maternal separation, an established model of stressor exposure early in life, alters microbiome composition in monkeys and rats. This change has been shown to be associated with exaggerated visceral pain responses in the rat that persist in adulthood (Barouei et al., 2012). Thus, the early neonatal period is also critical for the development of the neural nociceptive pathways and sensory nerves. Stress experienced in early life triggers long-term changes in visceral sensitivity to noxious stimuli (visceral hypersensitivity).

\subsubsection{Evidence from animal models}

Probiotics have been shown to balance altered microbiome in these syndromes, particularly in animal models. Some evidences will be provided next. Different evidences have shown that administration of probiotic bacteria modifies neuronal excitability and motility in animal models. Thus, administration of Lactobacillus species (L. rhamnosus, L. reuteri) increases enteric neuron excitability and modulates intestinal motility in rodents (Kunze et al., 2009; Wang et al., 2010a, 2010b). Lactobacillus farciminis exerts antinociceptive effects by altering central sensitization (Ait-Belgnaoui et al., 2009).

Lactobacillus spp. have been implicated in the modulation of visceral pain. For example, excitability of dorsal root ganglia in response to colorectal distension is prevented by L. rhamnosus treatment (Ma et al., 2009), and, in another study, treatment with Lactobacillus species up regulated mu-opioid and cannabinoid receptors expression in rats and mice, leading to visceral analgesia (Rousseaux et al., 2007). Also, the efficacy of 3 different probiotics (Lactobacillus salivarius UCC118, B. infantis 35624, and Bifidobacterium breve UCC2003) on the abdominal response to colorectal distension was compared using visceral normosensitive rats (SpragueDawley) and visceral hypersensitive rats (Wistar Kyoto), and only B. infantis 35624 was able to reduce the colorectal distension-induced pain behavior in both rat strains 
(McKernan et al., 2010), suggesting that strain specificity might be a key factor to consider when using probiotics to treat/avoid visceral pain.

In the rat, instillation of zymosan into the colon during the neonatal period produced short-term inflammation and subsequent long-term colonic hypersensitivity. Chronic visceral hypersensitivity occurring in adulthood in these animals was attenuated by L. rhamnosus ATCC 53103 (Lactobacillus GG; LGG) and, to a lesser extent, by a prebiotic mix (galactooligosaccharides and polydextrose) (Kannampalli et al., 2014). Furthermore, LGG was found to alter the levels of brain neurotransmitters, like serotonin, noradrenaline, and dopamine, all involved in pain modulation (Marks et al., 2009). Treatment with live and killed L. reuteri prevented the pain response to colorectal distension by decreasing distension-induced electrophysiological neuronal activity in the dorsal root ganglion (Kamiya et al., 2006). A decrease of normal visceral perception and chronic colonic hypersensitivity, elicited by butyrate was also observed after oral treatment with L. acidophilus NCFM (Rousseaux et al., 2007).

Acute and chronic stress models are widely used as IBS-like models, since stress induces gut hyper-permeability and visceral hypersensitivity in response to colorectal distension (Theodorou et al., 2014). For example, chronic fatigue was induced in rats by forcing them to swim in water till exhaustion (prolonged forced swim test). In this test, oral administration of Lactobacillus acidophilus significantly decreased immobility and post-swim fatigue time and attenuated oxido-nitrosative stress and TNF- $\alpha$ levels (Singh et al., 2012). Additionally, in two stress models in rats (acute restraint stress and neonatal maternal deprivation), 3 probiotic strains were evaluated: Bifidobacterium lactis (NCC362), Lactobacillus johnsonii (NCC533), and Lactobacillus paracasei (NCC2461) (Lpa). Only treatment with Lpa significantly improved stress-induced visceral pain and restored normal gut permeability, further highlighting that particular live bacteria strains and their metabolites generated in the medium may be required to improve stress-induced IBS-like symptoms (Eutamene et al., 2007).

A recent work by Darbarky (Darbaky et al., 2017) showed that treatment with two probiotics derived from the probiotic bacterial strain Lactobacillus rhamnosus may attenuate peripherally and centrally induced visceral hypersensitivity in rats, and it was suggested that it may be active in the treatment of IBS symptoms. 
Finally, in the IBS rat model of neonatal maternal separation, early life administration of VSL\#3 reduced visceral pain perception and reset colonic expression of subsets of genes mediating pain and inflammation (Distrutti et al., 2013), suggesting that changing the neurochemical milieu during the painful experience can modify the changes in visceral pain responses induced during infancy.

\subsubsection{Evidence from clinical studies}

There are some systematic reviews and meta-analysis that have explored the probiotic effects on abdominal or visceral pain in IBS. In general, results show a significant reduction of pain in both adults and children population after probiotics treatment (Didari et al., 2015).

A recent review has found moderate- to low-quality evidence suggesting that probiotics may be effective in improving pain in children with recurrent abdominal pain (Newlove-Delgado et al., 2017). In the same population (paediatric abdominal pain-related FGID), L. rhamnosus (GG and VSL\#3) were associated with significantly more responders to treatment (Rutten et al., 2015).

In a clinical trial, comparing an 8-week treatment with B. infantis (35624) and $L$. salivarius (UCC118) in IBS patients, only B. infantis (35624) treated patients experienced a reduction in individual scores for abdominal pain and discomfort, bloating and distension (O'Mahony et al., 2005). However, also related to adults with IBS, a recent meta-analysis showed that treatment with $B$. infantis 35624 did not impact on abdominal pain, whereas patients who received a mixture of probiotics containing $B$. infantis had significantly reduced abdominal pain, suggesting that $B$. infantis (35624) combined with other probiotic strains could be more effective to manage pain in IBS patients (Yuan et al., 2017).

Another effective probiotic strain capable of managing abdominal pain in IBS patients is $S$. cerevisiae (CNCM I-3856). This strain significantly improved the symptoms, with a $12.3 \%$ reduction of abdominal pain (Cayzeele-Decherf et al., 2017).

Therefore, according to all the evidences cited above, probiotics seem to be effective treatments for pain management in IBS. However, which individual species and strains are most beneficial remains unclear (Ford et al., 2014). 


\section{EVALUATION OF PROBIOTICS IN PAIN DISORDERS}

Until now, a relatively limited number of studies has investigated the influence of gut microbiota on pain and nociceptive processes (Rea et al., 2017). Indeed, most of the research has focused on IBS, one of the FGID with more evidence for the effectiveness of probiotics administration (Didari et al., 2015; Tiequn et al., 2015). As previously mentioned, evidence for the use of prebiotics in IBS come from from animal studies and are mainly based on their ability (i) to modulate visceral sensitivity and (ii) to enhance intestinal barrier function and immunity (Theodorou et al., 2014).

Although preclinical studies have focused on IBS models, clinical studies have also addressed the role of probiotics in chronic fatigue syndrome and other conditions. Indeed, there is some evidence for the effectiveness of probiotics in Chronic Fatigue Syndrome. In an exploratory study, Sullivan and colleagues (Sullivan et al., 2009) evaluated the effect of L. paracasei ssp. Paracasei F19, L. acidophilus NCFB 1748 and B. lactis Bb12 on fatigue and physical activity in 15 patients diagnosed with Chronic Fatigue Syndrome. Participants improved their neurocognitive functions, although no significant changes were reported either in fatigue or in the other variables measured, related to health and physical activity (Sullivan et al., 2009). Rao and colleagues (2009) found that patients with Chronic Fatigue Syndrome, treated for two months with Lactobacillus casei strain Shirota (LCS), showed a significant improvement in anxiety as compared with placebo (Rao et al., 2009). Groeger and colleages (2013) assessed the impact of the oral administration of $B$. infantis (35624), for 6-8 weeks, in patients with Chronic Fatigue Syndrome; inflammatory biomarkers and plasma cytokine levels were evaluated, but not only, and results showed that the probiotic treatment reduced plasma levels of C-reactive protein, IL- 6 and TNF- $\alpha$ in Chronic Fatigue Syndrome (Groeger et al., 2013).

Probiotics have also revealed their efficacy in the management of rheumatoid arthritis. The combination of the probiotic, Bacillus coagulans (GBI-30,6086) with the standard anti-arthritic medication, for 60 days, notably enhanced analgesia, as evidenced by an improvement in the Pain Scale as well as in the Patient Pain Assessment score. In addition, a greater improvement in patient global assessment and self-assessed disability was also assessed after the probiotic administration (Mandel et al., 2010). An additional study showed that the administration of 
Lactobacillus casei (01), for 8 weeks, to patients diagnosed with rheumatoid arthritis, induced a decrease in the disease activity score and significantly improved the inflammatory status of these patients. Probiotics seemed to decrease proinflammatory cytokines: tumor necrosis factor-alpha (TNF $\alpha$ ), IL-6, and IL-12, although no changes were observed in IL-1 $\beta$ levels (Vaghef-Mehrabany et al., 2014). Therefore, probiotics may emerge as a potential adjunctive therapy for rheumatoid arthritis patients.

Despite a theoretical rationale for a probiotic therapy in other pathologies such as spondyloarthritis, no benefits have been demonstrated in clinical trials. The combination of probiotics, Streptococcus salivarius (K12), Bifidobacterium lactis (LAFTI B94), and Lactobacillus acidophilus (LAFTI L10), for 12 weeks, did not achieve any difference over placebo in any of the core domains analysed: Bath Ankylosing Spondylitis Disease Activity Index (BASDAI), Bath Ankylosing Spondylitis Functional Index (BASFI), Maastricht Ankylosing Spondylitis Enthesitis Score (MASES). Thus, in this randomized controlled trial, the probiotic combination administered did not demonstrate significant benefit over placebo (Jenks et al., 2010).

\section{APPLICATION OF PROBIOTICS IN EMOTIONAL DISORDERS}

As already described, microbiota plays an essential role in Gl diseases (Martin and Kochhar, 2015), and, surprisingly, its seems also to be critically related to brain physiology and behaviour, thus possibly affecting mental health (Borre et al., 2014; Carabotti et al., 2015; Cryan and Dinan, 2012; Dinan et al., 2014). Actually, probiotics have emerged as a potential intervention to manage anxiety and depression, at least, in animal models. Indeed, the term psychobiotics was coined to describe the beneficial effects of probiotics in patients suffering from psychiatric illnesses (Dinan et al., 2013).

\subsection{Evidence from preclinical models}

Preclinical studies have focused on anxiety and depression (Huang et al., 2016). The administration of probiotics consistently induces anxiolytic- and anti-depressivelike responses in rodents. The chronic administration of Lactobacillus rhamnosus (JB-1) enhanced the exploration of the open-arms of an elevated plus-maze, indicative of an anxiolytic-like effect, although animals did not change their behavior in the stressinduced hyperthermia test. Moreover, the stress-induced corticosterone response was 
significantly attenuated by the administration of this probiotic (Bravo et al., 2011). Similar results have been reported in rats, tested in the elevated plus maze, following the administration of Lactobacillus fermentum (strain NS9) (Wang et al., 2015), in mice, evaluated in the Barnes test, after Lactobacillus helveticus (RO052) administration (Ohland et al., 2013), as well as in germ-free mice administered with Lactobacillus plantarum (PS128) and evaluated in the elevated plus-maze (Liu et al., 2016a).

More importantly, probiotics also act as effective anxiolytics in animal models with an anxious phenotype. Animals exposed to a protocol of early life stress, maternal separation ( 3 h/day from days 4 to 19), present an altered activity of the hypothalamus-pituitary-adrenal (HPA) axis demonstrating increased basal serum corticosterone levels; the administration of a mixture of two strains of Lactobacillus species was able to revert the enhanced level of circulating corticosterone (Gareau et al., 2007). In mice, Lactobacillus helveticus (ROO52) successfully prevented the negative effects of a Western-style diet on anxiety (Ohland et al., 2013). Immunodeficient mice, B and T cell-deficient Rag1(-/-) mice, exhibit increased anxiety levels, in the light-dark box, as well as augmented levels of circulating corticosterone; the administration of a mixture of Lactobacillus was able to prevent the former without affecting the HPA axis activity (Smith et al., 2014). However, some negative data have also been reported, e.g. the administration of Lactobacillus rhamnosus (NCC4007) was not effective in the management of the anxious state reported in an animal model of low-grade colitis (Bercik et al., 2010), although, in this case, the administration of another probiotic, Bifidobacterium longum (NCC3001), successfully reverted the anxiety-like behavior associated to chronic colitis (Bercik et al., 2010, 2011). The combination of Lactobacillus Helveticus (R0052) and Bifidobacterium longum (R0175) has also been investigated, and promising anxiolyticlike effects were reported in rats by using the conditioned defensive burying test of anxiety (Messaoudi et al., 2011). More recently, the administration of Lactobacillus rhamnosus (JB-1) was able to prevent the stress-induced anxiety-like behavior observed in mice chronically exposed to social defeat. In the study, L. rhamnosus (JB1) successfully prevented the deficits in social interaction with conspecifics although this probiotic was not able to counteract the avoidance to the aggressor, thus 
indicating a possible dissociation between several forms of anxiety-like behavior (Bharwani et al., 2017).

The vagus nerve seems to play a pivotal role in the anxiety-like effects of probiotics. The anxiolytic-like effects of L. rhamnosus (JB-1) were not found in vagotomized mice (Bravo et al., 2011). Moreover, in the chronic colitis animal model, anxiety-like behavior is vagally mediated, and the anxiolytic effect of $B$.longum required vagal integrity (Bercik et al., 2011). Bacteria may alter the excitability of enteric neurons, which may signal to the central nervous system by activating vagal pathways at the level of the ENS. Some other neuroactive substances released by gut bacteria, such as serotonin, noradrenaline, and dopamine, may also be involved in the emotional effects of probiotics. Potential mechanisms underlying the emotional actions of probiotics will be discussed in the next section.

Regarding antidepressant-like effects, controversial data have been reported. The chronic administration of Lactobacillus rhamnosus (JB-1) significantly reduced the time animals spent immobile in the forced swim test (FST) (Bravo et al., 2011) whereas Lactobacillus plantarum (PS128) administered to germ-free (GF) mice did not affect depression-like behaviors in the FST (Liu et al., 2016a). However, results become consistent if probiotics are tested in "depressed" animals. Bifidobacterium infantis (35624) effectively reversed the depressive phenotype of animals submitted to the maternal separation protocol (Desbonnet et al., 2010), and L. helveticus (NS8) demonstrated its antidepressant properties in the chronic restraint stress model of depression (Liang et al., 2015); in these two studies probiotics had similar effects than the usually prescribed antidepressant citalopram (Desbonnet et al., 2010; Liang et al., 2015). In addition, the combination of probiotics (L. helveticus and B. longum) was effective in the prevention of depressive-like symptoms associated to an animal model of myocardial infarction, in particular, this combination reversed the behavioral despair, the abnormal social interaction levels as well as the impaired processing of emotional memory reported following the surgical intervention (Arseneault-Bréard et al., 2012).

It is worth mentioning that probiotics have shown a positive impact in cognitive function. Recent studies have reported that mice fed with L. rhamnosus (JB-1) displayed an enhanced memory towards cues and context (Bravo et al., 2011); and 
mice fed with $B$. longum (1714) performed better in the object recognition test (discriminating faster between the two objects than other groups), in the Barnes maze (performing less errors than other groups) as well as in the fear conditioning test (Savignac et al., 2015). Notably, probiotics do not only seem to improve cognition per se but they are also able to counteract the memory impairments reported in several animal models. As an example, Lactobacillus fermentum (strain NS9) alleviated the ampicillin-induced impairment in memory retention evaluated in the Morris water maze (Wang et al., 2015); and Lactobacillus helveticus (ROO52) prevented the memory impairment associated to a Western-style diet (Ohland et al., 2013).

Insert Table 1 around here

Finally, results from animal models give further support to the potential anxiolytic and anti-depressant properties of probiotics. Recent studies have also proposed probiotics, in particular Lactobacillus rhamnosus (GG), as a valid strategy for the treatment of obsessive-compulsive disorder (OCD) since it effectively normalized the hyperlocomotion, stereotypes and perseverative behavior observed in an animal model of this disorder (Kantak et al., 2014). Probiotics have opened new avenues in the management of emotional disorders, however little is known yet regarding the underlying mechanisms.

\subsection{Evidence from human studies}

The reported anxiolytic and anti-depressant properties of probiotics may be effectively translated into the human population, although further studies and clinical trials are still needed.

One of the first studies, by Benton and colleagues (2007), was a double-blind placebo-controlled trial in which a yogurt containing L. Casei Shirota, or a placebo, was administered for 3 weeks. Despite the probiotic did not generally change the mood, a trend for improving the mood in those that were more depressed was reported. In line with this observation, Lactobacillus casei strain Shirota (LCS) administered daily for two months to a population suffering from Chronic Fatigue Syndrome provoked a decrease in anxiety symptoms evaluated by using the Beck Depression and Anxiety Inventories (Rao et al., 2009). The combination of Lactobacillus Helveticus (R0052) and Bifidobacterium longum (R0175) seems also to be useful as an anti-stress/anti-anxiety 
agent in healthy volunteers (Messaoudi et al., 2011). In the same line, a recent research show that $B$. longum 1714 strain alone can ameliorate both the physiological and psychological response to an acute stressor, as well as longer-term daily selfreported psychological stress, in healthy human adults. In addition, in the group treated with the probiotic a subtle improvement in visuospatial memory performance, as well as an EEG profile consistent with improved memory was observed (Allen et al., 2016). However, in a more recent study, Lactobacillus rhamnosus (JB-1) was not superior to placebo in modifying stress-related measures in healthy male participants evaluated during and after a socially evaluated cold pressor test (SECPT) (Kelly et al., 2017).

In parallel with the findings in preclinical studies, in humans, the administration of probiotics arises as a more powerful tool when treating altered emotional states. Probiotics effectively ameliorated anxiety symptoms in laryngeal cancer patients before surgery (Yang et al., 2016). Also, Lactobacillus rhamnosus HN001 (HN001) reduced the levels of depression and anxiety scores in the postpartum period (Slykerman et al., 2017). Probiotics administration, Lactobacillus casei strain Shirota (LCS), exerted beneficial effects preventing the onset of physical, physiological, and psychological symptoms reported in healthy subjects exposed to a stressful situation, an authorized nationwide examination for promotion (Kato-Kataoka et al., 2016). Authors propose that both the HPA axis and the serotonin system could be affected by probiotics, and may thus account, at least partially, to their anxiolytic-like actions (Kato-Kataoka et al., 2016).

Food supplementation with a multispecies probiotic has been proposed as a strategy to reduce negative thoughts associated with sad mood, and thus it might be used as a potential preventive strategy for depression (Steenbergen et al., 2015). Indeed, an altered microbiota composition has been reported in patients diagnosed with major depressive disorder (MDD) (Jiang et al., 2015). More recently, the antidepressant properties of probiotics have been confirmed in a depressed population. A clinical study has been performed analyzing the effects of probiotic intake in patients with MDD; the probiotic administration effectively decreased the depressive score of these patients (Akkasheh et al., 2016). Actually, probiotics, in a yogurt or in a multispecies probiotic capsule, have induced significant improvements 
both in a General health questionnaire (GHQ) as well as in the Depression anxiety and stress scale (DASS) in petrochemical workers (Mohammadi et al., 2016).

\section{Insert Table 2 around here}

Moreover, the brain response to probiotics has also been investigated by functional Magnetic Resonance Imaging (fMRI). Pinto-Sanchez and co-workers (2017) evaluate in a prospective study the effects of Bifidobacterium longum NCC3001 (BL) on anxiety and depression in patients with IBS. They found that BL reduces depression but not anxiety scores and increases quality of life. In addition, the fMRI analysis showed that $\mathrm{BL}$ reduced responses to negative emotional stimuli in multiple brain areas as amygdala. In other study, a small population of healthy women was exposed to a probiotic, containing Bifidobacterium animalis subsp Lactis, Streptococcus thermophiles, Lactobacillus bulgaricus, and Lactococcus lactis subsp Lactis, and then tested in the fMRI by using an emotional faces attention task and resting brain activity. The study revealed that this probiotic affected activity of brain regions that control central processing of emotion and sensation (Tillisch et al., 2013). In a more recent research in healthy women Tillisch and co-workers (2017) identified two clusters of subjects defined by the genera Bacteroides and Prevotella. The Prevotella group showed less hippocampal activity viewing negative valences images and was associated with differences in emotional, attentional, and sensory processing regions. For gray matter, the Bacteroides cluster showed greater prominence in the cerebellum, frontal regions, and the hippocampus. However, if the microbiota brain connections showed reflect the modulation of the gut microbiota structure the brain, or the influence of the microbiota on the brain and its affective responses, is still unknown.

\section{PUTATIVE MECHANISMS UNDERLYING THE CENTRAL EFFECTS OF PROBIOTICS}

Probiotics, as previously exposed, play a relevant role in the management of $\mathrm{Gl}$, emotional and pain-related disorders. Many mechanisms have been shown to be involved in this bidirectional pathway between the microbiota and the brain. Communication through the neural pathway is mainly mediated through the vagus 
nerve and the ENS. The HPA axis - via glucocorticoids - as well as the immunological pathway - through the modulation of cytokines - seem to be essential in this communication. More recently, microbiota has been proposed as an epigenetic entity (Stilling et al., 2014). However, the mechanisms involved in their effects are still under discussion [see (Carabotti et al., 2015; Cryan and Dinan, 2012; El Aidy et al., 2016; Wall et al., 2014) for an updated review of the topic].

Probiotics may alter emotionality and pain perception by acting on the central nervous system. Increased neuron excitability has been reported at several levels of the brain-gut axis, i.e., ENS, spinal cord and supraspinal sites (Feng et al., 2012). At the supra-spinal sites, interactions with emotional or stressful influences can modulate the visceral sensitivity resulting in increased pain perception (Hertig et al., 2007).

The vagus nerve has emerged as a crucial factor in the emotional effects of probiotics. As previously reported the anxiolytic-like effects of L. rhamnosus (JB-1) were not found in vagotomized mice (Bravo et al., 2011), and B. longum required vagal integrity to exert its anxiolytic effects in an animal model of colitis-induced anxiety (Bercik et al., 2011). B. longum metabolites decreased excitability of enteric neurons (Bercik et al., 2011) which may in turn signal to the central nervous system by activating vagal pathways at the level of the ENS. The anxiolytic actions of probiotics may be vagally mediated, however, as much as we are concerned, the involvement of vagal nerve in the analgesic effects of probiotics has not yet been investigated.

Gut microbiota produce several microbial metabolites such as short chain fatty acids, vitamins and chemotactic peptides (Bercik and Collins, 2014; De Palma et al., 2014; Sherwin et al., 2016) that can bind to receptors expressed on enteroendocrine cells to facilitate secretion of a variety of peptides that can act locally on nearby intestinal epithelium and immune cells, can activate neurons of the ENS, and can also act in remote sites such as the brain (Furness et al., 2013).

Increasing data give support to microbially produced molecules with neuroactive functions such as $\gamma$-aminobutyric acid (GABA), serotonin, catecholamines and acetylcholine which can modulate neural signalling within the enteric nervous system, when released in the intestinal lumen, and consequently interfere with brain function and behaviour (Patterson et al., 2014). Actually, many of these neurotransmitters have been isolated from bacteria within the human gut (Wall et al., 
2014). Chronic live PS128 ingestion significantly increased the levels of both serotonin and dopamine in the striatum, but not in the prefrontal cortex or hippocampus (Liu et al., 2016a). The administration of Bifidobacterium infantis was able to restore basal NA concentrations in the brainstem of animals exposed to early maternal separation (Desbonnet et al., 2010). L. helveticus (NS8) restored hippocampal serotonin and norepinephrine levels in an animal model of depression, the chronic stress in rats (Liang et al., 2015). In humans, some species of Lactobacillus have been reported to prevent the increase in plasma L-tryptophan, a precursor of serotonin, detected before the exposure to a certain stress, and was able to increase the concentration of fecal serotonin in the long term (Kato-Kataoka et al., 2016). Region-dependent alterations in $G A B A_{A}$ and $G_{B B A}$ receptor expression have been described following chronic treatment with $L$. rhamnosus $(J B-1)$. The probiotic induced an increase in $G_{A B A}$ in cortical regions (cingulate and prelimbic) and concomitant reductions in the hippocampus, amygdala, and locus coeruleus; while $\mathrm{GABA}_{\mathrm{A}}$ exhibited a reduction in the prefrontal cortex and amygdala, but an increase in the hippocampus (Bravo et al., 2011).

Neurotrophins, and more specifically Brain Derived Neurotrophic Factor (BDNF), has been given a central role in the pathophysiology of depression. The administration of $B$ longum restored the diminished hippocampal BDNF levels observed in an animal model of low-grade colitis (Bercik et al., 2010). Actually, the administration of L. helveticus (NS8) increased hippocampal BDNF mRNA expression, thus suggesting a common mechanism of action between probiotics and actual antidepressants (Liang et al., 2015). However, discrepant results in which no changes in BDNF levels were observed have also been reported for B. longum (Bercik et al., 2011).

The HPA axis might also been involved in the microbiota-brain interaction. Despite inconsistencies, probiotics have been reported to affect the HPA activation. $L$. helveticus (NS8) resulted in lower plasma corticosterone (CORT) and adrenocorticotropic hormone (ACTH) levels (Liang et al., 2015); and Bifidobacterium infantis restored the MS-induced changes in amygdala corticotrophin-releasing factor (CRF) mRNA levels (Desbonnet et al., 2010). These changes in the HPA activation might 
play a critical role in the emotional actions of probiotics, although the connection pathway between microbiota and the HPA axis deserves further investigation.

Probiotics may also alter emotionality and pain perception by acting via microbiota-immune interactions. Cytokines produced in the $\mathrm{Gl}$ tract might be able to cross the blood-brain barrier, affecting the central nervous system, and thus possibly modulating mood and behavior. L. helveticus (NS8) resulted in higher plasma IL-10 levels (Liang et al., 2015), whereas Bifidobacterium infantis, normalized the enhanced peripheral IL-6 release reported in the maternal separation animal model (Desbonnet et al., 2010).

Pain relief actions of probiotics have been related with the opioid and the cannabinoid system. Treatment with Lactobacillus species in an animal model of IBD up-regulated colonic mu-opioid receptor (MOR) and cannabinoid receptor 2 (CB2R) expression in rats, together with a reduction in visceral sensitivity (Rousseaux et al., 2007). In humans with mild to moderate abdominal pain, the probiotic Lactobacillus acidophilus (NCFM) induced an increase in colonic MOR expression, as well as downstream signaling as measured by enterocyte STAT3-phosphorylation. In contrast, CB2R expression was decreased (Ringel-Kulka et al., 2014). Although the opioid system emerges as a plausible mechanism of action by which probiotics modulates pain sensation in humans, research on the role played by the endocannabinoid system deserves further investigation. More recently, feeding rats with Lactobacillus reuteri (DSM 17938) inhibited perception of painful gastric distension and the vanilloid receptor TRPV1 has emerged as a specific target channel for a probiotic with potential therapeutic properties (Perez-Burgos et al., 2015).

Esto es lo que nos dice que metamos el segundo referee..yo la verdad, no lo veo...como no sea aquí en las conclusiones, no veo donde encaja

"Due to studies in humans can only assign correlations and not causality, a new model in which a human fecal microbiota is established in germ-free mice through microbiota transplantation (HMA) has been employed. However, there is some limitations of this models that need to be elucidated. For example, whether the donor human microbiota was successfully transplanted into the mice and whether the human dysbiosis patterns were reproduced is still unknown (Arrieta et al., 2016)." 
Dietary supplementation with probiotics and prebiotics are the most widely used dietary adjuncts to modulate the gut microbiota. Furthermore, evidence is emerging of the interactions between administered microbes and dietary substrates, leading to the production of pharmabiotics, which may directly or indirectly positively influence human health (Patterson et al., 2014).

CHALLENGES: In choosing a probiotic strategy, clinicians should adhere to the principles of evidence-based therapeutics. These include: selection from a reputable supplier, with appropriate documentation of contents and shelf life; anticipation of strain-specific effects; avoidance of cocktails without documentation of the activities of each ingredient with absence of interstrain antagonism; and published evidence of efficacy from clinical trials (Shanahan and Collins, 2010).

The translational study carry out with Kelly and co-workers (2017) (Kelly et al., 2017) in healthy volunteers they failed to replicate their preclinical findings. These research highlights the challenges in translating the findings from candidate psychobiotics in stresssusceptible animals, to healthy human populations. One of these challenges in translation from animals to humans requiere a cultural change for the food and probiotic industry to carry out the level of investment required for such clinical trials to prove efficacy (Dinan and Cryan, 2016).

Therefore, translation into human clinical investigations and the results of large-scale placebo-controlled trials are still awaited. Further investigation is needed to fully understand how gut microbes influence the brain (Dinan and Cryan, 2016).

\section{CONCLUSIONS AND FUTURE PERSPECTIVES}

Probiotics appear to be a safe strategy in the management of several GI, emotional and pain disorders. Most evidences come from animal models, but the translation from animal studies to the clinics still deserves further investigation. The design and performance of larger trials is urgently needed to verify whether these new strategies might be useful not only for the treatment of disorders affecting the Gl tract but, 
importantly, also emotional and pain disorders not directly related to the GI tract. In this regard, we have recently described a protocol for the evaluation of the efficacy of probiotics in fibromyalgia (Roman et al., 2017). The future application of probiotics in the clinic should take into consideration important aspects. The clinical desired effects may be specific of a particular specie of bacteria. To optimize the effects of probiotic specific combinations of bacteria might be of special interest, although the combination with other nutrients and/or nutraceuticals, or even the design of the vehicles may play a critical role in their effects (Nguyen et al., 2016). Last but not least, a better understanding of the mechanisms involved may open new avenues in the design of therapeutics that could enhance the clinical benefits pursued. 
Tables

TABLE 1. Effects of probiotic administration on emotional disorders: Evidence from animal models.

\begin{tabular}{lllll}
\hline Reference & Animal model & Probiotic administration & Test & Main findings \\
\hline Lactobacillus & & & & \\
\hline (Gareau et al., 2007) & $\begin{array}{l}\text { Sprague- } \\
\text { Dawley rats }\end{array}$ & $\begin{array}{l}\text { Mixture Lactobacillus: } \\
\text { L. Rhamnosus (R0011, }\end{array}$ & HPA & $\begin{array}{l}\text { No changes in corticosterone levels in } \\
\text { control animals. }\end{array}$ \\
& & & \\
& & & \\
& & & \\
& & & \\
& & &
\end{tabular}

The augmented basal corticosterone levels observed in MS animals were

Animal model: Neonatal maternal separation (MS) normalized.

$\begin{array}{lllll}\text { (Bravo et al., 2011) } & \begin{array}{l}\text { Mice } \\ \text { Balb-c }\end{array} & \begin{array}{l}\text { L. Rhamnosus (JB-1) } \\ \text { Chronic } \\ 28 \text { days }\end{array} & \text { SIH } & \text { No effects } \\ & \text { EPM } & \text { Increased open-arm entries } \\ & \text { OF } & \text { Increased time in the central } \\ & \text { FST } & \text { Decrease immobility time }\end{array}$

\begin{tabular}{|c|c|c|}
\hline nd et al., 2013) & 129/SvEv mice & L. Helveticus (R0052) \\
\hline
\end{tabular}
21 days

(Smith et al., 2014) C57BL/6 mice Mixture Lactobacillus: L. Increased exploration of the light rhamnosus (R0011); L. Compartment in basal conditions and helveticus (R0052) in following psychological stress. maltodextrin.

4 weeks

Animal model: Immunodeficiency (Rag 1-/-)

HPA No changes in corticosterone levels.

*No effects of probiotics were evaluated in wild type mice.

\begin{tabular}{lllll}
\hline (Wang et al., 2015b) & Rats & $\begin{array}{l}\text { L. Fermentum (NS9) } \\
30 \text { days }\end{array}$ & EPM & Anxiolytic-like response \\
\hline (Liu et al., 2016b) & $\begin{array}{l}\text { Germ-free } \\
\text { C57BL/6JNarl } \\
\text { mice }\end{array}$ & $\begin{array}{l}\text { L. Plantarum (PS128) } \\
\text { Chronic } \\
16 \text { days }\end{array}$ & OFT & $\begin{array}{l}\text { Increased locomotor activity } \\
\text { Did not affect time spent in the } \\
\text { central area. }\end{array}$ \\
& EPM & $\begin{array}{l}\text { Increased the ratio of time spent in } \\
\text { the open arm compared with time } \\
\text { spent in the closed arm. }\end{array}$ \\
\hline (Bercik et al., 2010) & AKR mice & $\begin{array}{l}\text { L. rhamnosus (NCC4007) } \\
\text { 10 days }\end{array}$ & FST & No changes in immobility time \\
& & HPA & No changes in corticosterone levels. \\
\hline
\end{tabular}


Animal model of low-grade colitis.

SD

Did not affect behavior.

*No effects of probiotics were evaluated in normal animals.

\begin{tabular}{|c|c|c|c|c|}
\hline \multirow[t]{5}{*}{ (Liang et al., 2015) } & \multirow{5}{*}{$\begin{array}{l}\text { Sprague-Dawley } \\
\text { rats, specific } \\
\text { pathogen free }\end{array}$} & \multirow{5}{*}{$\begin{array}{l}\text { L. Helveticus (NS8) } \\
26 \text { days }\end{array}$} & SPT & Reverted the anhedonia observed. \\
\hline & & & EPM & $\begin{array}{l}\text { Reverted the anxiety-like responses } \\
\text { observed. }\end{array}$ \\
\hline & & & OF & Improved behavior. \\
\hline & & & HPA & $\begin{array}{l}\text { Lower plasma corticosterone and } \\
\text { adrenocorticotropic hormone (ACTH) } \\
\text { levels. }\end{array}$ \\
\hline & & & ORT & Counteracted cognitive deficits. \\
\hline \multicolumn{3}{|c|}{ Animal model: Chronic Restraint Stress depression model. } & OPT & Improved cognition. \\
\hline \multirow[t]{3}{*}{$\begin{array}{l}\text { (Bharwani et al., } \\
\text { 2017) }\end{array}$} & \multirow[t]{3}{*}{ C57BL/6 mice } & \multirow[t]{3}{*}{$\begin{array}{l}\text { L. rhamnosus (JB-1) } \\
28 \text { days }\end{array}$} & OF & $\begin{array}{l}\text { Attenuated the observed deficit in } \\
\text { rearing, exploratory activity. }\end{array}$ \\
\hline & & & LD & $\begin{array}{l}\text { Visited the light compartment more } \\
\text { frequently, anxiolytic-like effect. }\end{array}$ \\
\hline & & & $\begin{array}{l}\text { Social } \\
\text { Preference }\end{array}$ & $\begin{array}{l}\text { Showed no preference between the } \\
\text { social-no social chambers. }\end{array}$ \\
\hline \multicolumn{3}{|c|}{ Animal model of depression: chronic social defeat. } & $\begin{array}{l}\text { Aggressor- } \\
\text { approach }\end{array}$ & $\begin{array}{l}\text { Continued to exhibit a marked } \\
\text { avoidance to their aggressor. }\end{array}$ \\
\hline
\end{tabular}

\section{Bifidobacterium}

(Bercik et al., 2010) AKR mice

B. longum (NCC3001)
10 days

LD

Reversed the anxious state observed.

Animal model of low-grade colitis: parasite infection.

SD

Reversed the anxious state observed.

*No effects of probiotics were evaluated in normal animals.

$\begin{array}{lll}\text { (Bercik et al., 2011) AKR mice } & \begin{array}{l}\text { B. longum (NCC3001) SD } \\ 1 \text { week }\end{array}\end{array}$

Animal model of chronic colitis: low dose dextran sodium

sulfate (DSS) administration.

* No effects of probiotics were evaluated in normal animals.

\begin{tabular}{|c|c|c|c|c|}
\hline $\begin{array}{l}\text { (Desbonnet et al., } \\
\text { 2010) }\end{array}$ & Rats & B. infantis (35624) & FST & $\begin{array}{l}\text { Reversed the depressive-like } \\
\text { behaviours observed in MS animals }\end{array}$ \\
\hline
\end{tabular}

Animal model: Neonatal maternal separation (MS)

\begin{tabular}{lll}
\hline (Savignac et al., & BALB/c mice & $\begin{array}{l}\text { B. Longum (1724); B. Breve } \\
\text { (1205). }\end{array}$ \\
& 6 weeks
\end{tabular}

$\begin{array}{cl}\text { Barnes maze } & \text { Performed fewer errors. } \\ \begin{array}{c}\text { Fear } \\ \text { conditioning }\end{array} & \text { Better learning and memory. }\end{array}$




\section{Combination: Lactobacillus \& Bifidobacterium}

\begin{tabular}{lllll}
$\begin{array}{l}\text { (Messaoudi et al., } \\
\text { 2011) }\end{array}$ & $\begin{array}{l}\text { Wistar } \\
\text { Rats }\end{array}$ & $\begin{array}{l}\text { L. helveticus (R0052); B. } \\
\text { Longum (R0175). } \\
\text { 2 weeks }\end{array}$ & CDB & $\begin{array}{l}\text { Lower stress/anxiety score; effects } \\
\text { similar to diazepam. }\end{array}$ \\
$\begin{array}{l}\text { (Arseneault-Bréard } \\
\text { et al., 2012) }\end{array}$ & $\begin{array}{l}\text { Sprague- } \\
\text { Dawley rats }\end{array}$ & $\begin{array}{l}\text { L. helveticus (R0052); B. } \\
\text { Longum (R0175). } \\
7 \text { days + 11 days }\end{array}$ & SI & $\begin{array}{l}\text { Returned social interaction to sham } \\
\text { levels. }\end{array}$ \\
Animal model of myocardial infarction (MI) & FST & $\begin{array}{l}\text { Normalized the MI-induced behavioral } \\
\text { despair. }\end{array}$ \\
\hline
\end{tabular}

Abbreviations: HPA, HPA axis activity; SIH, Stress-induced hyperthermia; OF, Open field test; EPM, Elevated Plus-Maze; FST, Forced Swim Test; LD, Light-Dark Box; SD, step-down test; SPT, sucrose preference test; ORT, object recognition test; OPT, object placement test; SI, Social Interaction; CDB, Conditioned defensive burying. 
TABLE 2. Effects of probiotic administration on emotional disorders: Evidence from human studies.

\begin{tabular}{llll}
\hline Reference & Population Probiotic administration & Measurement & Main findings
\end{tabular}

Lactobacillus

(Benton et al., 2007)

$\begin{array}{cc}\text { General } & \text { L. Casei Shirota } \\ \text { population } & 3 \text { months }\end{array}$

Mood and Cognition

The probiotic did not generally

change the mood.

(132 persons)

However, a trend for improved mood in those that were more depressed was observed.

An unexpected and possibly chance finding was that the consumption of probiotics resulted in a slightly poorer performance on two measures of memory.

\begin{tabular}{|c|c|c|c|c|}
\hline (Rao et al., 2009) & $\begin{array}{l}\text { Chronic Fatigue } \\
\text { Syndrome } \\
\text { patients } \\
\text { (39 patients) }\end{array}$ & $\begin{array}{l}\text { L. casei strain Shirota } \\
\text { (LcS) } \\
2 \text { months }\end{array}$ & $\begin{array}{l}\text { Beck Depression and } \\
\text { Anxiety Inventories }\end{array}$ & $\begin{array}{l}\text { A decrease in anxiety } \\
\text { symptoms. }\end{array}$ \\
\hline \multirow[t]{4}{*}{$\begin{array}{l}\text { (Kato-Kataoka et al., } \\
\text { 2016) }\end{array}$} & $\begin{array}{l}\text { Healthy medical } \\
\text { students }\end{array}$ & $\begin{array}{l}\text { Lactobacillus casei strain } \\
\text { Shirota (LCS) }\end{array}$ & Psychophysical state & $\begin{array}{l}\text { Lower reports of abdominal } \\
\text { and cold symptoms. }\end{array}$ \\
\hline & (47 students) & 8 weeks & Salivary cortisol & $\begin{array}{l}\text { The elevation observed before } \\
\text { the examination in the } \\
\text { placebo group was not } \\
\text { evidenced. }\end{array}$ \\
\hline & & & Plasma L-tryptophan & $\begin{array}{l}\text { The elevation observed before } \\
\text { the examination in the } \\
\text { placebo group was not } \\
\text { evidenced. }\end{array}$ \\
\hline & & & Faecal serotonin & $\begin{array}{l}\text { Increased two weeks after the } \\
\text { examination. }\end{array}$ \\
\hline
\end{tabular}

Subjects were exposed to stress, i.e. an authorized nationwide examination for promotion.

\begin{tabular}{|c|c|c|c|c|}
\hline \multirow[t]{2}{*}{$\begin{array}{l}\text { (Slykerman et al., } \\
\text { 2017) }\end{array}$} & $\begin{array}{l}\text { Women recruited } \\
\text { at } 14-16 \text { weeks } \\
\text { gestation } \\
(380)\end{array}$ & $\begin{array}{l}\text { Lactobacillus rhamnosus } \\
\text { HN001 } \\
\text { From enrollment up } \\
\text { till six months post-birth } \\
\text { whilst breastfeeding. }\end{array}$ & $\begin{array}{l}\text { Edinburgh Postnatal } \\
\text { Depression Scale } \\
\text { (EPDS) }\end{array}$ & $\begin{array}{l}\text { Women who received HNOO1 } \\
\text { had significantly lower } \\
\text { depression in the postpartum } \\
\text { period. }\end{array}$ \\
\hline & & & $\begin{array}{l}\text { State Trait Anxiety } \\
\text { Inventory } 6 \text { item } \\
\text { version (STAI6) }\end{array}$ & $\begin{array}{l}\text { Women who received HNOO1 } \\
\text { had significantly lower anxiety } \\
\text { score in the postpartum } \\
\text { period. }\end{array}$ \\
\hline (Kelly et al., 2017) & $\begin{array}{l}\text { Healthy male } \\
\text { volunteers } \\
\text { (29 participants) }\end{array}$ & $\begin{array}{l}\text { L. rhamnosus (JB-1) } \\
8 \text { weeks }\end{array}$ & $\begin{array}{l}\text { Self-report stress } \\
\text { measures } \\
\text { Salivary cortisol }\end{array}$ & $\begin{array}{l}\text { No overall effect on mood or } \\
\text { anxiety. } \\
\text { No changes }\end{array}$ \\
\hline
\end{tabular}




$\begin{array}{cl}\begin{array}{c}\text { Resting } \\ \text { electroencephalogra } \\ \text { phy (EEG). }\end{array} & \text { No effects on sleep quality } \\ \text { Cognitive } & \begin{array}{l}\text { Visuospatial memory } \\ \text { performance, attention } \\ \text { swessments }\end{array} \\ \begin{array}{c}\text { switching, rapid visual } \\ \text { information processing were } \\ \text { not affected } \\ \text { cytokine levels by } \\ \text { ELISA }\end{array} & \begin{array}{l}\text { No changes observed. } \\ \text { nalimulated }\end{array}\end{array}$

Subjects were exposed to stress, i.e. a socially evaluated cold pressor test (SECPT).

\section{Clostridium}

\begin{tabular}{|c|c|c|c|c|}
\hline \multirow[t]{3}{*}{ (Yang et al., 2016) } & $\begin{array}{l}\text { Patients with } \\
\text { laryngeal cancer } \\
\qquad(30) \text { and } \\
\text { Healthy } \\
\text { volunteers (20) }\end{array}$ & $\begin{array}{c}\text { Clostridium } \\
\text { butyricum } \\
2 \text { weeks before surgery }\end{array}$ & Heart rate & $\begin{array}{l}\text { Prevented the increase before } \\
\text { surgery }\end{array}$ \\
\hline & & & Serum CRF levels & $\begin{array}{l}\text { Prevented the increase before } \\
\text { surgery }\end{array}$ \\
\hline & & & $\begin{array}{l}\text { Hamilton Anxiety } \\
\text { Scale (HAMA) }\end{array}$ & Relieved the degree of anxiety \\
\hline \multicolumn{5}{|l|}{ Bifidobacterium } \\
\hline \multirow[t]{3}{*}{ (Allen et al., 2016) } & $\begin{array}{l}\text { Healthy male } \\
\text { volunteers } \\
\text { (22 participants) }\end{array}$ & $\begin{array}{c}\text { Bifidobacterium longum } \\
1714 \\
4 \text { weeks }\end{array}$ & $\begin{array}{l}\text { Cohen Perceived } \\
\text { Stress Scale }\end{array}$ & $\begin{array}{l}\text { Ameliorate both the } \\
\text { physiological and } \\
\text { psychological response to an } \\
\text { acute stressor, as well as } \\
\text { longer-term daily self- } \\
\text { reported psychological stress }\end{array}$ \\
\hline & & & $\begin{array}{l}\text { Cognitive } \\
\text { assessments }\end{array}$ & $\begin{array}{l}\text { A subtle improvement in } \\
\text { visuospatial memory } \\
\text { performance }\end{array}$ \\
\hline & & & $\begin{array}{c}\text { Resting } \\
\text { electroencephalogra } \\
\text { phy }\end{array}$ & $\begin{array}{l}\text { An EEG profile consistent with } \\
\text { improved memory was } \\
\text { observed }\end{array}$ \\
\hline
\end{tabular}

\section{Combination: Lactobacillus \& Bifidobacterium}

(Messaoudi et al., 2011).

$\begin{array}{cc}\text { Healthy } & \text { L. Helveticus (R0052); } \\ \text { Caucasian } & \text { B. longum (R0175) } \\ \text { (66 men and } & 30 \text { days } \\ \text { woman) } & \end{array}$

Hopkins Symptom Checklist (HSCL-90)

Lower global severity index, due to lower values for somatisation, depression and angerhostility.

Hospital Anxiety and Depression Scale (HADS)
Diminished HADS global scores 


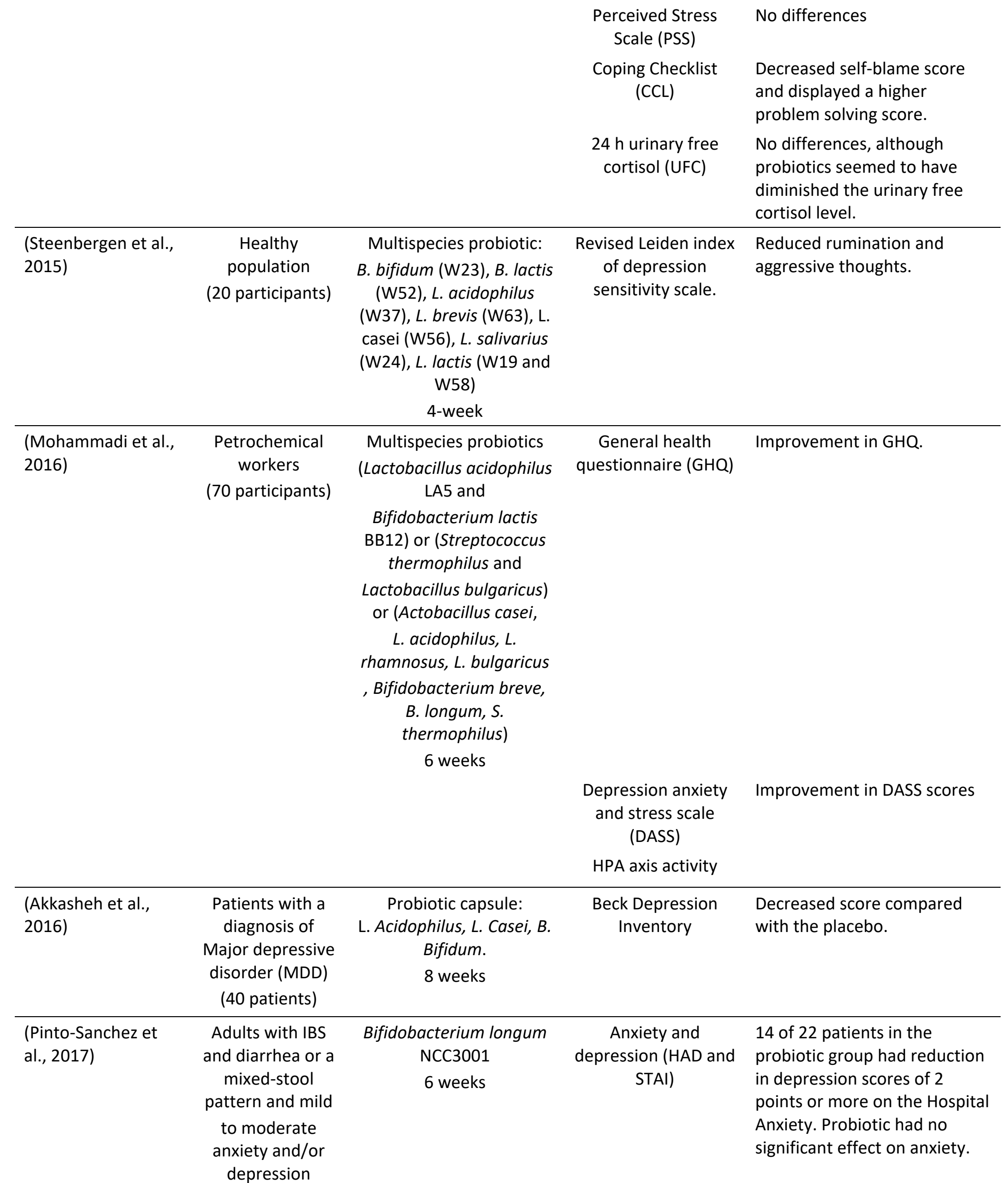




\section{(44 patients)}

\begin{tabular}{|c|c|}
\hline $\begin{array}{l}\text { IBS symptoms and } \\
\text { signs (Birmingham } \\
\text { IBS score and Bristol } \\
\text { stool scale) }\end{array}$ & $\begin{array}{l}\text { Probiotic had no significant } \\
\text { effect on IBS symptoms }\end{array}$ \\
\hline $\begin{array}{l}\text { Health related } \\
\text { quality of life (Short } \\
\text { Form Health Suvery } \\
\text { (SF)-36) }\end{array}$ & $\begin{array}{l}\text { Patients in the probiotic group } \\
\text { had a mean increase in quality } \\
\text { of life score compared with } \\
\text { the placebo group }\end{array}$ \\
\hline $\begin{array}{c}\text { Somatization } \\
\text { (Patient Health } \\
\text { Questionnaire-15) }\end{array}$ & $\begin{array}{l}\text { Somatization scores were } \\
\text { similar in both groups } \\
\text { (placebo and probiotic) }\end{array}$ \\
\hline Brain activity (fMRI) & $\begin{array}{l}\text { Probiotic reduced responses } \\
\text { to negative emotional stimuli } \\
\text { in multiple brain areas }\end{array}$ \\
\hline $\begin{array}{l}\text { Blood and urine } \\
\text { samples }\end{array}$ & $\begin{array}{l}\text { Probiotic and placebo had } \\
\text { similar serum markers of } \\
\text { inflammation, and levels of } \\
\text { neurotrophins and } \\
\text { neurotransmitters. Probiotic } \\
\text { group had reduced urine } \\
\text { levels of methylamines and } \\
\text { aromatic amino acids } \\
\text { metabolites }\end{array}$ \\
\hline Microbiota analysis & $\begin{array}{l}\text { Probiotic and placebo had } \\
\text { similar fecal microbiota } \\
\text { profiles }\end{array}$ \\
\hline
\end{tabular}




\section{References}

Adams, C. A. (2010). The probiotic paradox: live and dead cells are biological response modifiers. Nutr. Res. Rev. 23, 37-46. doi:10.1017/S0954422410000090.

Aguilera, M., Cerdà-Cuéllar, M., and Martínez, V. (2015). Antibiotic-induced dysbiosis alters host-bacterial interactions and leads to colonic sensory and motor changes in mice. Gut Microbes 6, 10-23. doi:10.4161/19490976.2014.990790.

Ait-Belgnaoui, A., Eutamene, H., Houdeau, E., Bueno, L., Fioramonti, J., and Theodorou, V. (2009). Lactobacillus farciminis treatment attenuates stress-induced overexpression of Fos protein in spinal and supraspinal sites after colorectal distension in rats. Neurogastroenterol. Motil. 21, 567-73, e18-9. doi:10.1111/j.1365-2982.2009.01280.x.

Akkasheh, G., Kashani-Poor, Z., Tajabadi-Ebrahimi, M., Jafari, P., Akbari, H., Taghizadeh, M., et al. (2016). Clinical and metabolic response to probiotic administration in patients with major depressive disorder: A randomized, double-blind, placebo-controlled trial. Nutrition 32, 315-320. doi:10.1016/j.nut.2015.09.003.

Al-Nedawi, K., Mian, M. F., Hossain, N., Karimi, K., Mao, Y.-K., Forsythe, P., et al. (2015). Gut commensal microvesicles reproduce parent bacterial signals to host immune and enteric nervous systems. FASEB J. 29, 684-95. doi:10.1096/fj.14-259721.

Allen, A. P., Hutch, W., Borre, Y. E., Kennedy, P. J., Temko, A., Boylan, G., et al. (2016). Bifidobacterium longum 1714 as a translational psychobiotic: modulation of stress, electrophysiology and neurocognition in healthy volunteers. Transl. Psychiatry 6, e939. doi:10.1038/tp.2016.191.

Arseneault-Bréard, J., Rondeau, I., Gilbert, K., Girard, S.-A., Tompkins, T. A., Godbout, R., et al. (2012). Combination of Lactobacillus helveticus R0052 and Bifidobacterium longum R0175 reduces post-myocardial infarction depression symptoms and restores intestinal permeability in a rat model. Br. J. Nutr. 107, 1793-1799.

doi:10.1017/S0007114511005137.

Bäckhed, F., Ley, R. E., Sonnenburg, J. L., Peterson, D. A., and Gordon, J. I. (2005). Hostbacterial mutualism in the human intestine. Science 307, 1915-20. doi:10.1126/science.1104816.

Bailey, J. R., Vince, V., Williams, N. A., and Cogan, T. A. (2017). Streptococcus thermophilus NCIMB 41856 ameliorates signs of colitis in an animal model of inflammatory bowel disease. Benef. Microbes, 1-10. doi:10.3920/BM2016.0110.

Balzola, F., Bernstein, C., Ho, G. T., and Lees, C. (2010). A human gut microbial gene catalogue established by metagenomic sequencing: Commentary. Inflamm. Bowel Dis. Monit. 11, 28. doi:10.1038/nature08821.

Barbara, G., Cremon, C., De Giorgio, R., Dothel, G., Zecchi, L., Bellacosa, L., et al. (2011). Mechanisms underlying visceral hypersensitivity in irritable bowel syndrome. Curr. Gastroenterol. Rep. 13, 308-15. doi:10.1007/s11894-011-0195-7.

Barouei, J., Moussavi, M., and Hodgson, D. M. (2012). Effect of maternal probiotic intervention on HPA axis, immunity and gut microbiota in a rat model of irritable bowel syndrome. PLoS One 7, e46051. doi:10.1371/journal.pone.0046051.

Benton, D., Williams, C., and Brown, A. (2007). Impact of consuming a milk drink containing a probiotic on mood and cognition. Eur. J. Clin. Nutr. 61, 355-361.

doi:10.1038/sj.ejcn.1602546. 
Bercik, P., and Collins, S. M. (2014). The effects of inflammation, infection and antibiotics on the microbiota-gut-brain axis. Adv. Exp. Med. Biol. 817, 279-89. doi:10.1007/978-1-49390897-4_13.

Bercik, P., Park, A. J., Sinclair, D., Khoshdel, A., Lu, J., Huang, X., et al. (2011). The anxiolytic effect of Bifidobacterium longum NCC3001 involves vagal pathways for gut-brain communication. Neurogastroenterol. Motil. 23, 1132-1139. doi:10.1111/j.13652982.2011.01796.x.

Bercik, P., Verdu, E. F., Foster, J. A., Macri, J., Potter, M., Huang, X., et al. (2010). Chronic Gastrointestinal Inflammation Induces Anxiety-Like Behavior and Alters Central Nervous System Biochemistry in Mice. Gastroenterology 139, 2102-2112.e1. doi:10.1053/j.gastro.2010.06.063.

Beyder, A., Mazzone, A., Strege, P. R., Tester, D. J., Saito, Y. A., Bernard, C. E., et al. (2014). Loss-of-function of the voltage-gated sodium channel NaV1.5 (channelopathies) in patients with irritable bowel syndrome. Gastroenterology 146, 1659-68. doi:10.1053/j.gastro.2014.02.054.

Bezkorovainy, A. (2001). Probiotics: determinants of survival and growth in the gut. Am. J. Clin. Nutr. 73, 399S-405S. Available at: http://www.ncbi.nlm.nih.gov/pubmed/11157348.

Bharwani, A., Mian, M. F., Surette, M. G., Bienenstock, J., and Forsythe, P. (2017). Oral treatment with Lactobacillus rhamnosus attenuates behavioural deficits and immune changes in chronic social stress. BMC Med. 15, 7. doi:10.1186/s12916-016-0771-7.

Blaut, M., and Clavel, T. (2007). Metabolic diversity of the intestinal microbiota: implications for health and disease. J. Nutr. 137, 751S-5S. Available at: http://www.ncbi.nlm.nih.gov/pubmed/17311972.

Boltin, D. (2016). Probiotics in Helicobacter pylori-induced peptic ulcer disease. Best Pract. Res. Clin. Gastroenterol. 30, 99-109. doi:10.1016/j.bpg.2015.12.003.

Borre, Y. E., Moloney, R. D., Clarke, G., Dinan, T. G., and Cryan, J. F. (2014). The impact of microbiota on brain and behavior: Mechanisms \& therapeutic potential. Adv. Exp. Med. Biol. 817, 373-403. doi:10.1007/978-1-4939-0897-4_17.

Bravo, J. A., Forsythe, P., Chew, M. V., Escaravage, E., Savignac, H. M., Dinan, T. G., et al. (2011). Ingestion of Lactobacillus strain regulates emotional behavior and central GABA receptor expression in a mouse via the vagus nerve. Proc. Natl. Acad. Sci. 108, 1605016055. doi:10.1073/pnas.1102999108.

Burokas, A., Arboleya, S., Moloney, R. D., Peterson, V. L., Murphy, K., Clarke, G., et al. (2017). Targeting the Microbiota-Gut-Brain Axis: Prebiotics Have Anxiolytic and Antidepressantlike Effects and Reverse the Impact of Chronic Stress in Mice. Biol. Psychiatry 82, 472487. doi:10.1016/j.biopsych.2016.12.031.

Camilleri, M., Lasch, K., and Zhou, W. (2012). Irritable bowel syndrome: methods, mechanisms, and pathophysiology. The confluence of increased permeability, inflammation, and pain in irritable bowel syndrome. Am. J. Physiol. Gastrointest. Liver Physiol. 303, G775-85. doi:10.1152/ajpgi.00155.2012.

Carabotti, M., Scirocco, A., Maselli, M. A., and Severi, C. (2015). The gut-brain axis: interactions between enteric microbiota, central and enteric nervous systems. Ann. Gastroenterol. $Q$. Publ. Hell. Soc. Gastroenterol. 28, 203-209.

Cayzeele-Decherf, A., Pélerin, F., Leuillet, S., Douillard, B., Housez, B., Cazaubiel, M., et al. 
(2017). Saccharomyces cerevisiae CNCM I-3856 in irritable bowel syndrome: An individual subject meta-analysis. World J. Gastroenterol. 23, 336. doi:10.3748/wjg.v23.i2.336.

Chassard, C., Dapoigny, M., Scott, K. P., Crouzet, L., Del'homme, C., Marquet, P., et al. (2012). Functional dysbiosis within the gut microbiota of patients with constipated-irritable bowel syndrome. Aliment. Pharmacol. Ther. 35, 828-38. doi:10.1111/j.13652036.2012.05007.x.

Chen, Z.-F., Ai, L.-Y., Wang, J.-L., Ren, L.-L., Yu, Y.-N., Xu, J., et al. (2015). Probiotics Clostridium butyricum and Bacillus subtilis ameliorate intestinal tumorigenesis. Future Microbiol. 10, 1433-45. doi:10.2217/fmb.15.66.

Chichlowski, M., and Rudolph, C. (2015). Visceral pain and gastrointestinal microbiome. J. Neurogastroenterol. Motil. 21, 172-81. doi:10.5056/jnm15025.

Chitapanarux, I., Chitapanarux, T., Traisathit, P., Kudumpee, S., Tharavichitkul, E., and Lorvidhaya, V. (2010). Randomized controlled trial of live lactobacillus acidophilus plus bifidobacterium bifidum in prophylaxis of diarrhea during radiotherapy in cervical cancer patients. Radiat. Oncol. 5, 31. doi:10.1186/1748-717X-5-31.

Constante, M., Fragoso, G., Lupien-Meilleur, J., Calvé, A., and Santos, M. M. (2017). Iron Supplements Modulate Colon Microbiota Composition and Potentiate the Protective Effects of Probiotics in Dextran Sodium Sulfate-induced Colitis. Inflamm. Bowel Dis. 23, 753-766. doi:10.1097/MIB.0000000000001089.

Cryan, J. F., and Dinan, T. G. (2012). Mind-altering microorganisms: the impact of the gut microbiota on brain and behaviour. Nat. Rev. Neurosci. 13, 701-12. doi:10.1038/nrn3346.

Darbaky, Y., Evrard, B., Patrier, S., Falenta, J., Garcin, S., Tridon, A., et al. (2017). Oral probiotic treatment of Lactobacillus rhamnosus Lcr35 $\left({ }^{\circledR}\right)$ prevents visceral hypersensitivity to a colonic inflammation and an acute psychological stress. J. Appl. Microbiol. 122, 188-200. doi:10.1111/jam.13320.

De Palma, G., Collins, S. M., Bercik, P., and Verdu, E. F. (2014). The microbiota-gut-brain axis in gastrointestinal disorders: stressed bugs, stressed brain or both? J. Physiol. 592, 2989-97. doi:10.1113/jphysiol.2014.273995.

Deng, H., Li, Z., Tan, Y., Guo, Z., Liu, Y., Wang, Y., et al. (2016). A novel strain of Bacteroides fragilis enhances phagocytosis and polarises M1 macrophages. Sci. Rep. 6, 29401. doi:10.1038/srep29401.

Derwa, Y., Gracie, D. J., Hamlin, P. J., and Ford, A. C. (2017). Systematic review with metaanalysis: the efficacy of probiotics in inflammatory bowel disease. Aliment. Pharmacol. Ther. doi:10.1111/apt.14203.

Desbonnet, L., Garrett, L., Clarke, G., Kiely, B., Cryan, J. F., and Dinan, T. G. (2010). Effects of the probiotic Bifidobacterium infantis in the maternal separation model of depression. Neuroscience 170, 1179-1188. doi:10.1016/j.neuroscience.2010.08.005.

Didari, T., Mozaffari, S., Nikfar, S., and Abdollahi, M. (2015). Effectiveness of probiotics in irritable bowel syndrome: Updated systematic review with meta-analysis. World J. Gastroenterol. 21, 3072-3084. doi:10.3748/wjg.v21.i10.3072.

Dinan, T., Borre, Y., and Cryan, J. (2014). Genomics of schizophrenia: time to consider the gut microbiome\&quest; Mol. Psychiatry 19, 1252-1257. doi:10.1038/mp.2014.93.

Dinan, T. G., and Cryan, J. F. (2016). Mood by microbe: towards clinical translation. Genome 
Med. 8, 36. doi:10.1186/s13073-016-0292-1.

Dinan, T. G., Stanton, C., and Cryan, J. F. (2013). Psychobiotics: A novel class of psychotropic. Biol. Psychiatry 74, 720-726. doi:10.1016/j.biopsych.2013.05.001.

Distrutti, E., Cipriani, S., Mencarelli, A., Renga, B., and Fiorucci, S. (2013). Probiotics VSL\#3 protect against development of visceral pain in murine model of irritable bowel syndrome. PLoS One 8, e63893. doi:10.1371/journal.pone.0063893.

El Aidy, S., Stilling, R., Dinan, T. G., and Cryan, J. F. (2016). Microbiome to Brain: Unravelling the Multidirectional Axes of Communication. Adv. Exp. Med. Biol. 874, 301-36. doi:10.1007/978-3-319-20215-0_15.

Eutamene, H., Lamine, F., Chabo, C., Theodorou, V., Rochat, F., Bergonzelli, G. E., et al. (2007). Synergy between Lactobacillus paracasei and its bacterial products to counteract stressinduced gut permeability and sensitivity increase in rats. J. Nutr. 137, 1901-7. Available at: http://www.ncbi.nlm.nih.gov/pubmed/17634262.

Fabisiak, A., Włodarczyk, J., Fabisiak, N., Storr, M., and Fichna, J. (2017). Targeting Histamine Receptors in Irritable Bowel Syndrome: A Critical Appraisal. J. Neurogastroenterol. Motil. 23, 341-348. doi:10.5056/jnm16203.

Feng, B., La, J. H., Schwartz, E. S., and Gebhart, G. F. (2012). Irritable bowel syndrome: methods, mechanisms, and pathophysiology. Neural and neuro-immune mechanisms of visceral hypersensitivity in irritable bowel syndrome. Am. J. Physiol. Gastrointest. Liver Physiol. 302, G1085-98. doi:10.1152/ajpgi.00542.2011.

Fisher, L., and Fisher, A. (2017). Acid-Suppressive Therapy and Risk of Infections: Pros and Cons. Clin. Drug Investig. 37, 587-624. doi:10.1007/s40261-017-0519-y.

Fond, G., Boukouaci, W., Chevalier, G., Regnault, A., Eberl, G., Hamdani, N., et al. (2015). The "psychomicrobiotic": Targeting microbiota in major psychiatric disorders: A systematic review. Pathol. Biol. 63, 35-42. doi:10.1016/j.patbio.2014.10.003.

Ford, A. C., Quigley, E. M. M., Lacy, B. E., Lembo, A. J., Saito, Y. A., Schiller, L. R., et al. (2014). Efficacy of Prebiotics, Probiotics, and Synbiotics in Irritable Bowel Syndrome and Chronic Idiopathic Constipation: Systematic Review and Meta-analysis. Am. J. Gastroenterol. 109, 1547-1561. doi:10.1038/ajg.2014.202.

Furness, J. B., Rivera, L. R., Cho, H.-J., Bravo, D. M., and Callaghan, B. (2013). The gut as a sensory organ. Nat. Rev. Gastroenterol. Hepatol. 10, 729-40. doi:10.1038/nrgastro.2013.180.

Ganji-Arjenaki, M., and Rafieian-Kopaei, M. (2017). Probiotics are a good choice in remission of inflammatory bowel diseases: A meta analysis and systematic review. J. Cell. Physiol. doi:10.1002/jcp.25911.

Gareau, M. G., Jury, J., MacQueen, G., Sherman, P. M., and Perdue, M. H. (2007). Probiotic treatment of rat pups normalises corticosterone release and ameliorates colonic dysfunction induced by maternal separation. Gut 56, 1522-1528. doi:10.1136/gut.2006.117176.

Gisbert, J. P. (2016). Helicobacter pylori-related diseases. Gastroenterol. Hepatol. 39 Suppl 1, 36-46. doi:10.1016/S0210-5705(16)30173-X.

Groeger, D., O'Mahony, L., Murphy, E. F., Bourke, J. F., Dinan, T. G., Kiely, B., et al. (2013). Bifidobacterium infantis 35624 modulates host inflammatory processes beyond the gut. 
Gut Microbes 4, 325-339. doi:10.4161/gmic.25487.

Guarner, F. (2005). The intestinal flora in inflammatory bowel disease: normal or abnormal? Curr. Opin. Gastroenterol. 21, 414-8. Available at: http://www.ncbi.nlm.nih.gov/pubmed/15930980.

Haghshenas, B., Abdullah, N., Nami, Y., Radiah, D., Rosli, R., and Khosroushahi, A. Y. (2014). Different effects of two newly-isolated probiotic Lactobacillus plantarum $15 \mathrm{HN}$ and Lactococcus lactis subsp. Lactis 44Lac strains from traditional dairy products on cancer cell lines. Anaerobe 30, 51-9. doi:10.1016/j.anaerobe.2014.08.009.

Haghshenas, B., Abdullah, N., Nami, Y., Radiah, D., Rosli, R., and Yari Khosroushahi, A. (2015). Microencapsulation of probiotic bacteria Lactobacillus plantarum $15 \mathrm{HN}$ using alginatepsyllium-fenugreek polymeric blends. J. Appl. Microbiol. 118, 1048-57. doi:10.1111/jam.12762.

Hardy, H., Harris, J., Lyon, E., Beal, J., and Foey, A. D. (2013). Probiotics, prebiotics and immunomodulation of gut mucosal defences: homeostasis and immunopathology. Nutrients 5, 1869-912. doi:10.3390/nu5061869.

Hertig, V. L., Cain, K. C., Jarrett, M. E., Burr, R. L., and Heitkemper, M. M. (2007). Daily stress and gastrointestinal symptoms in women with irritable bowel syndrome. Nurs. Res. 56, 399-406. doi:10.1097/01.NNR.0000299855.60053.88.

Hill, C., Guarner, F., Reid, G., Gibson, G. R., Merenstein, D. J., Pot, B., et al. (2014). Expert consensus document: The International Scientific Association for Probiotics and Prebiotics consensus statement on the scope and appropriate use of the term probiotic. Nat. Rev. Gastroenterol. Hepatol. 11, 9. doi:10.1038/nrgastro.2014.66.

Holtmann, G. J., Ford, A. C., and Talley, N. J. (2016). Pathophysiology of irritable bowel syndrome. lancet. Gastroenterol. Hepatol. 1, 133-146. doi:10.1016/S24681253(16)30023-1.

Huang, R., Wang, K., and Hu, J. (2016). Effect of probiotics on depression: A systematic review and meta-analysis of randomized controlled trials. Nutrients 8, 483. doi:10.3390/nu8080483.

Hughes, P. A., Zola, H., Penttila, I. A., Blackshaw, L. A., Andrews, J. M., and Krumbiegel, D. (2013). Immune activation in irritable bowel syndrome: can neuroimmune interactions explain symptoms? Am. J. Gastroenterol. 108, 1066-74. doi:10.1038/ajg.2013.120.

Husebye, E., Hellström, P. M., and Midtvedt, T. (1994). Intestinal microflora stimulates myoelectric activity of rat small intestine by promoting cyclic initiation and aboral propagation of migrating myoelectric complex. Dig. Dis. Sci. 39, 946-56. Available at: http://www.ncbi.nlm.nih.gov/pubmed/8174436.

Ijiri, M., Fujiya, M., Konishi, H., Tanaka, H., Ueno, N., Kashima, S., et al. (2017). Ferrichrome identified from Lactobacillus casei ATCC334 induces apoptosis through its iron-binding site in gastric cancer cells. Tumour Biol. 39, 1010428317711311. doi:10.1177/1010428317711311.

Ivanovska, T. P., Mladenovska, K., Zhivikj, Z., Pavlova, M. J., Gjurovski, I., Ristoski, T., et al. (2017). Synbiotic loaded chitosan-Ca-alginate microparticles reduces inflammation in the TNBS model of rat colitis. Int. J. Pharm. 527, 126-134. doi:10.1016/j.ijpharm.2017.05.049.

Jenks, K., Stebbings, S., Burton, J., Schultz, M., Herbison, P., and Highton, J. (2010). Probiotic therapy for the treatment of spondyloarthritis: A randomized controlled trial. J. 
Rheumatol. 37, 2118-2125. doi:10.3899/jrheum.100193.

Jiang, H., Ling, Z., Zhang, Y., Mao, H., Ma, Z., Yin, Y., et al. (2015). Altered fecal microbiota composition in patients with major depressive disorder. Brain. Behav. Immun. 48, 186194. doi:10.1016/j.bbi.2015.03.016.

Kailasapathy, K. (2002). Microencapsulation of probiotic bacteria: technology and potential applications. Curr. Issues Intest. Microbiol. 3, 39-48. Available at: http://www.ncbi.nlm.nih.gov/pubmed/12400637.

Kamiya, T., Wang, L., Forsythe, P., Goettsche, G., Mao, Y., Wang, Y., et al. (2006). Inhibitory effects of Lactobacillus reuteri on visceral pain induced by colorectal distension in Sprague-Dawley rats. Gut 55, 191-6. doi:10.1136/gut.2005.070987.

Kandasamy, S., Vlasova, A. N., Fischer, D. D., Chattha, K. S., Shao, L., Kumar, A., et al. (2017). Unraveling the Differences between Gram-Positive and Gram-Negative Probiotics in Modulating Protective Immunity to Enteric Infections. Front. Immunol. 8, 334. doi:10.3389/fimmu.2017.00334.

Kannampalli, P., Pochiraju, S., Chichlowski, M., Berg, B. M., Rudolph, C., Bruckert, M., et al. (2014). Probiotic Lactobacillus rhamnosus GG (LGG) and prebiotic prevent neonatal inflammation-induced visceral hypersensitivity in adult rats. Neurogastroenterol. Motil. 26, 1694-704. doi:10.1111/nmo.12450.

Kantak, P. A., Bobrow, D. N., and Nyby, J. G. (2014). Obsessive-compulsive-like behaviors in house mice are attenuated by a probiotic (Lactobacillus rhamnosus GG). Behav. Pharmacol. 25, 71-9. doi:10.1097/FBP.0000000000000013.

Kao, A. C. C., Harty, S., and Burnet, P. W. J. (2016). "The Influence of Prebiotics on Neurobiology and Behavior," in International review of neurobiology, 21-48. doi:10.1016/bs.irn.2016.08.007.

Kato-Kataoka, A., Nishida, K., Takada, M., Suda, K., Kawai, M., Shimizu, K., et al. (2016). Fermented milk containing Lactobacillus casei strain Shirota prevents the onset of physical symptoms in medical students under academic examination stress. Benef. Microbes 7, 153-156. doi:10.3920/BM2015.0100.

Kaur, I. P., Chopra, K., and Saini, A. (2002). Probiotics: Potential pharmaceutical applications. Eur. J. Pharm. Sci. 15, 1-9. doi:10.1016/S0928-0987(01)00209-3.

Kelly, J. R., Allen, A. P., Temko, A., Hutch, W., Kennedy, P. J., Farid, N., et al. (2017). Lost in translation? The potential psychobiotic Lactobacillus rhamnosus (JB-1) fails to modulate stress or cognitive performance in healthy male subjects. Brain. Behav. Immun. 61, 5059. doi:10.1016/j.bbi.2016.11.018.

Khoder, G., Al-Menhali, A. A., Al-Yassir, F., and Karam, S. M. (2016). Potential role of probiotics in the management of gastric ulcer. Exp. Ther. Med. 12, 3-17. doi:10.3892/etm.2016.3293.

Koekkoek, K. W. A. C., and van Zanten, A. R. H. (2017). Nutrition in the critically ill patient. Curr. Opin. Anaesthesiol. 30, 178-185. doi:10.1097/ACO.0000000000000441.

Kunze, W. A., Mao, Y.-K., Wang, B., Huizinga, J. D., Ma, X., Forsythe, P., et al. (2009). Lactobacillus reuteri enhances excitability of colonic $\mathrm{AH}$ neurons by inhibiting calciumdependent potassium channel opening. J. Cell. Mol. Med. 13, 2261-70. doi:10.1111/j.1582-4934.2009.00686.x. 
Lau, C. S. M., Ward, A., and Chamberlain, R. S. (2016). Probiotics improve the efficacy of standard triple therapy in the eradication of Helicobacter pylori: a meta-analysis. Infect. Drug Resist. 9, 275-289. doi:10.2147/IDR.S117886.

Lee, H. J., Choi, J. K., Ryu, H. S., Choi, C. H., Kang, E. H., Park, K. S., et al. (2017). Therapeutic Modulation of Gut Microbiota in Functional Bowel Disorders. J. Neurogastroenterol. Motil. 23, 9-19. doi:10.5056/jnm16124.

Liang, S., Wang, T., Hu, X., Luo, J., Li, W., Wu, X., et al. (2015). Administration of Lactobacillus helveticus NS8 improves behavioral, cognitive, and biochemical aberrations caused by chronic restraint stress. Neuroscience 310, 561-577. doi:10.1016/j.neuroscience.2015.09.033.

Liang, S., Xu, L., Zhang, D., and Wu, Z. (2016). Effect of probiotics on small intestinal bacterial overgrowth in patients with gastric and colorectal cancer. Turk. J. Gastroenterol. 27, 22732. doi:10.5152/tjg.2016.15375.

Liu, W.-H., Chuang, H.-L., Huang, Y.-T., Wu, C.-C., Chou, G.-T., Wang, S., et al. (2016a). Alteration of behavior and monoamine levels attributable to Lactobacillus plantarum PS128 in germ-free mice. Behav. Brain Res. 298, 202-209. doi:10.1016/j.bbr.2015.10.046.

Liu, W., Ran, C., Liu, Z., Gao, Q., Xu, S., Ring ø, E., et al. (2016b). Effects of dietary Lactobacillus plantarum and $\mathrm{AHL}$ lactonase on the control of Aeromonas hydrophila infection in tilapia. Microbiologyopen 5, 687-699. doi:10.1002/mbo3.362.

Ma, X., Mao, Y.-K., Wang, B., Huizinga, J. D., Bienenstock, J., and Kunze, W. (2009). Lactobacillus reuteri ingestion prevents hyperexcitability of colonic DRG neurons induced by noxious stimuli. Am. J. Physiol. Gastrointest. Liver Physiol. 296, G868-75. doi:10.1152/ajpgi.90511.2008.

Mackowiak, P. A. (2013). Recycling metchnikoff: probiotics, the intestinal microbiome and the quest for long life. Front. public Heal. 1, 52. doi:10.3389/fpubh.2013.00052.

Mandel, D. R., Eichas, K., and Holmes, J. (2010). Bacillus coagulans: a viable adjunct therapy for relieving symptoms of rheumatoid arthritis according to a randomized, controlled trial. BMC Complement. Altern. Med. 10, 1. doi:10.1186/1472-6882-10-1.

Marin, M. L., Lee, J. H., Murtha, J., Ustunol, Z., and Pestka, J. J. (1997). Differential cytokine production in clonal macrophage and T-cell lines cultured with bifidobacteria. J. Dairy Sci. 80, 2713-20. doi:10.3168/jds.S0022-0302(97)76232-5.

Marks, D. M., Shah, M. J., Patkar, A. A., Masand, P. S., Park, G.-Y., and Pae, C.-U. (2009). Serotonin-norepinephrine reuptake inhibitors for pain control: premise and promise. Curr. Neuropharmacol. 7, 331-6. doi:10.2174/157015909790031201.

Martin, F.-P., and Kochhar, S. (2015a). "Introduction to Metabonomics in Systems Biology Research," in, 1-24. doi:10.1007/978-1-4471-6539-2_1.

Martin, F., and Kochhar, S. (2015b). Metabonomics and Gut Microbiota in Nutrition and Disease. , eds. S. Kochhar and F.-P. Martin London: Springer London doi:10.1007/978-14471-6539-2.

Mättö, J., Maunuksela, L., Kajander, K., Palva, A., Korpela, R., Kassinen, A., et al. (2005). Composition and temporal stability of gastrointestinal microbiota in irritable bowel syndrome--a longitudinal study in IBS and control subjects. FEMS Immunol. Med. Microbiol. 43, 213-22. Available at: http://www.ncbi.nlm.nih.gov/pubmed/15747442. 
Mayer, E. A. (2011). Gut feelings: the emerging biology of gut-brain communication. Nat. Rev. Neurosci. 12, 453-66. doi:10.1038/nrn3071.

Mayer, E. A., Tillisch, K., and Gupta, A. (2015). Gut/brain axis and the microbiota. J. Clin. Invest. 125, 926-38. doi:10.1172/JCI76304.

McKernan, D. P., Fitzgerald, P., Dinan, T. G., and Cryan, J. F. (2010). The probiotic Bifidobacterium infantis 35624 displays visceral antinociceptive effects in the rat. Neurogastroenterol. Motil. 22, 1029-35, e268. doi:10.1111/j.1365-2982.2010.01520.x.

Mearin, F., Ciriza, C., Mínguez, M., Rey, E., Mascort, J. J., Peña, E., et al. (2016). Clinical Practice Guideline: Irritable bowel syndrome with constipation and functional constipation in the adult. Rev. Esp. Enferm. Dig. 108, 332-63. doi:10.17235/reed.2016.4389/2016.

Messaoudi, M., Lalonde, R., Violle, N., Javelot, H., Desor, D., Nejdi, A., et al. (2011). Assessment of psychotropic-like properties of a probiotic formulation (Lactobacillus helveticus R0052 and Bifidobacterium longum R0175) in rats and human subjects. Br. J. Nutr. 105, 755764. doi:10.1017/S0007114510004319.

Mohammadi, A. A., Jazayeri, S., Khosravi-Darani, K., Solati, Z., Mohammadpour, N., Asemi, Z., et al. (2016). The effects of probiotics on mental health and hypothalamic-pituitaryadrenal axis: A randomized, double-blind, placebo-controlled trial in petrochemical workers. Nutr. Neurosci. 19, 87-135. doi:10.1179/1476830515Y.0000000023.

Nami, Y., Haghshenas, B., and Yari Khosroushahi, A. (2017). Effect of psyllium and gum Arabic biopolymers on the survival rate and storage stability in yogurt of Enterococcus duransIW3 encapsulated in alginate. Food Sci. Nutr. 5, 554-563. doi:10.1002/fsn3.430.

Neish, A. S. (2009). Microbes in Gastrointestinal Health and Disease. Gastroenterology 136, 65-80. doi:10.1053/j.gastro.2008.10.080.

Newlove-Delgado, T. V, Martin, A. E., Abbott, R. A., Bethel, A., Thompson-Coon, J., Whear, R., et al. (2017). Dietary interventions for recurrent abdominal pain in childhood. Cochrane Database Syst. Rev. 2017, CD010972. doi:10.1002/14651858.CD010972.pub2.

Nguyen, H.-T., Truong, D.-H., Kouhoundé, S., Ly, S., Razafindralambo, H., and Delvigne, F. (2016). Biochemical Engineering Approaches for Increasing Viability and Functionality of Probiotic Bacteria. Int. J. Mol. Sci. 17. doi:10.3390/ijms17060867.

O’Mahony, L., McCarthy, J., Kelly, P., Hurley, G., Luo, F., Chen, K., et al. (2005). Lactobacillus and bifidobacterium in irritable bowel syndrome: symptom responses and relationship to cytokine profiles. Gastroenterology 128, 541-51. Available at: http://www.ncbi.nlm.nih.gov/pubmed/15765388.

Ohland, C. L., and Jobin, C. (2015). Microbial activities and intestinal homeostasis: A delicate balance between health and disease. Cell. Mol. Gastroenterol. Hepatol. 1, 28-40. doi:10.1016/j.jcmgh.2014.11.004.

Ohland, C. L., Kish, L., Bell, H., Thiesen, A., Hotte, N., Pankiv, E., et al. (2013). Effects of Lactobacillus helveticus on murine behavior are dependent on diet and genotype and correlate with alterations in the gut microbiome. Psychoneuroendocrinology 38, 17381747. doi:10.1016/j.psyneuen.2013.02.008.

Ohman, L., and Simrén, M. (2010). Pathogenesis of IBS: role of inflammation, immunity and neuroimmune interactions. Nat. Rev. Gastroenterol. Hepatol. 7, 163-73.

doi:10.1038/nrgastro.2010.4. 
Ojekunle, O., Banwo, K., and Sanni, A. I. (2017). In vitro and in vivo evaluation of Weissella cibaria and Lactobacillus plantarum for their protective effect against cadmium and lead toxicities. Lett. Appl. Microbiol. 64, 379-385. doi:10.1111/lam.12731.

Orlando, A., Refolo, M. G., Messa, C., Amati, L., Lavermicocca, P., Guerra, V., et al. (2012). Antiproliferative and proapoptotic effects of viable or heat-killed Lactobacillus paracasei IMPC2.1 and Lactobacillus rhamnosus GG in HGC-27 gastric and DLD-1 colon cell lines. Nutr. Cancer 64, 1103-11. doi:10.1080/01635581.2012.717676.

Oshima, T., Nakajima, S., Yokoyama, T., Toyoshima, F., Sakurai, J., Tanaka, J., et al. (2010). The G-protein beta3 subunit 825 TT genotype is associated with epigastric pain syndrome-like dyspepsia. BMC Med. Genet. 11, 13. doi:10.1186/1471-2350-11-13.

Osterlund, P., Ruotsalainen, T., Korpela, R., Saxelin, M., Ollus, A., Valta, P., et al. (2007). Lactobacillus supplementation for diarrhoea related to chemotherapy of colorectal cancer: a randomised study. Br. J. Cancer 97, 1028-34. doi:10.1038/sj.bjc.6603990.

Patterson, E., Cryan, J. F., Fitzgerald, G. F., Ross, R. P., Dinan, T. G., and Stanton, C. (2014). Gut microbiota, the pharmabiotics they produce and host health. Proc. Nutr. Soc. 73, 477-89. doi:10.1017/S0029665114001426.

Perez-Burgos, A., Wang, L., McVey Neufeld, K.-A., Mao, Y.-K., Ahmadzai, M., Janssen, L. J., et al. (2015). The TRPV1 channel in rodents is a major target for antinociceptive effect of the probiotic Lactobacillus reuteri DSM 17938. J. Physiol. 593, 3943-57. doi:10.1113/JP270229.

Pinto-Sanchez, M. I., Hall, G. B., Ghajar, K., Nardelli, A., Bolino, C., Lau, J. T., et al. (2017). Probiotic Bifidobacterium longum NCC3001 Reduces Depression Scores and Alters Brain Activity: A Pilot Study in Patients With Irritable Bowel Syndrome. Gastroenterology 153, 448-459.e8. doi:10.1053/j.gastro.2017.05.003.

Quigley, E. M. M. (2013). Gut bacteria in health and disease. Gastroenterol. Hepatol. (N. Y). 9, 560-9. Available at: http://www.ncbi.nlm.nih.gov/pubmed/24729765.

Quigley, E. M. M. (2017). Gut microbiome as a clinical tool in gastrointestinal disease management: are we there yet? Nat. Rev. Gastroenterol. Hepatol. 14, 315-320. doi:10.1038/nrgastro.2017.29.

Rachmilewitz, D., Katakura, K., Karmeli, F., Hayashi, T., Reinus, C., Rudensky, B., et al. (2004). Toll-like receptor 9 signaling mediates the anti-inflammatory effects of probiotics in murine experimental colitis. Gastroenterology 126, 520-8. Available at: http://www.ncbi.nlm.nih.gov/pubmed/14762789.

Rajilić-Stojanović, M., Biagi, E., Heilig, H. G. H. J., Kajander, K., Kekkonen, R. A., Tims, S., et al. (2011). Global and deep molecular analysis of microbiota signatures in fecal samples from patients with irritable bowel syndrome. Gastroenterology 141, 1792-801. doi:10.1053/j.gastro.2011.07.043.

Rao, A. V., Bested, A. C., Beaulne, T. M., Katzman, M. A., lorio, C., Berardi, J. M., et al. (2009). A randomized, double-blind, placebo-controlled pilot study of a probiotic in emotional symptoms of chronic fatigue syndrome. Gut Pathog. 1, 6. doi:10.1186/1757-4749-1-6.

Rasouli, B. S., Ghadimi-Darsajini, A., Nekouian, R., and Iragian, G.-R. (2017). In vitro activity of probiotic Lactobacillus reuteri against gastric cancer progression by downregulation of urokinase plasminogen activator/urokinase plasminogen activator receptor gene expression. J. Cancer Res. Ther. 13, 246-251. doi:10.4103/0973-1482.204897. 
Rea, K., O'Mahony, S. M., Dinan, T. G., and Cryan, J. F. (2017). The role of the gastrointestinal microbiota in visceral pain. Handb. Exp. Pharmacol. 239, 269-287. doi:10.1007/164_2016_115.

Ringel-Kulka, T., Goldsmith, J. R., Carroll, I. M., Barros, S. P., Palsson, O., Jobin, C., et al. (2014). Lactobacillus acidophilus NCFM affects colonic mucosal opioid receptor expression in patients with functional abdominal pain - A randomised clinical study. Aliment. Pharmacol. Ther. 40, 200-207. doi:10.1111/apt.12800.

Rodríguez-Fandiño, O., Hernández-Ruiz, J., and Schmulson, M. (2010). From cytokines to tolllike receptors and beyond - current knowledge and future research needs in irritable bowel syndrome. J. Neurogastroenterol. Motil. 16, 363-73. doi:10.5056/jnm.2010.16.4.363.

Roman, P., Estevez, A. F., Sánchez-Labraca, N., Cañadas, F., Miras, A., and Cardona, D. (2017). Probiotics for Fibromyalgia: Study design for a pilot double-blind, randomized controlled trial. Nutr. Hosp. 34, 1285-1290. doi:10.20960/nh.1300.

Rousseaux, C., Thuru, X., Gelot, A., Barnich, N., Neut, C., Dubuquoy, L., et al. (2007). Lactobacillus acidophilus modulates intestinal pain and induces opioid and cannabinoid receptors. Nat. Med. 13, 35-7. doi:10.1038/nm1521.

Rutten, J. M. T. M., Korterink, J. J., Venmans, L. M. A. J., Benninga, M. A., and Tabbers, M. M. (2015). Nonpharmacologic Treatment of Functional Abdominal Pain Disorders: A Systematic Review. Pediatrics 135, 522-535. doi:10.1542/peds.2014-2123.

Saito, Y. A., Strege, P. R., Tester, D. J., Locke, G. R., Talley, N. J., Bernard, C. E., et al. (2009). Sodium channel mutation in irritable bowel syndrome: evidence for an ion channelopathy. Am. J. Physiol. Gastrointest. Liver Physiol. 296, G211-8. doi:10.1152/ajpgi.90571.2008.

Sakai, Y., Tsukahara, T., Bukawa, W., Matsubara, N., and Ushida, K. (2006). Cell preparation of Enterococcus faecalis strain EC-12 prevents vancomycin-resistant enterococci colonization in the cecum of newly hatched chicks. Poult. Sci. 85, 273-7. Available at: http://www.ncbi.nlm.nih.gov/pubmed/16523627.

Salas-Jara, M. J., Ilabaca, A., Vega, M., and García, A. (2016). Biofilm Forming Lactobacillus: New Challenges for the Development of Probiotics. Microorganisms 4. doi:10.3390/microorganisms4030035.

Salazar, N., Arboleya, S., Valdés, L., Stanton, C., Ross, P., Ruiz, L., et al. (2014). The human intestinal microbiome at extreme ages of life. Dietary intervention as a way to counteract alterations. Front. Genet. 5, 406. doi:10.3389/fgene.2014.00406.

Savignac, H. M., Kiely, B., Dinan, T. G., and Cryan, J. F. (2014). Bifidobacteria exert strainspecific effects on stress-related behavior and physiology in BALB/C mice. Neurogastroenterol. Motil. 26, 1615-1627. doi:10.1111/nmo.12427.

Savignac, H. M., Tramullas, M., Kiely, B., Dinan, T. G., and Cryan, J. F. (2015). Bifidobacteria modulate cognitive processes in an anxious mouse strain. Behav. Brain Res. 287, 59-72. doi:10.1016/j.bbr.2015.02.044.

Schwille-Kiuntke, J., Enck, P., Zendler, C., Krieg, M., Polster, A. V, Klosterhalfen, S., et al. (2011). Postinfectious irritable bowel syndrome: follow-up of a patient cohort of confirmed cases of bacterial infection with Salmonella or Campylobacter. Neurogastroenterol. Motil. 23, e479-88. doi:10.1111/j.1365-2982.2011.01779.x. 
Sender, R., Fuchs, S., and Milo, R. (2016). Are We Really Vastly Outnumbered? Revisiting the Ratio of Bacterial to Host Cells in Humans. Cell 164, 337-340. doi:10.1016/j.cell.2016.01.013.

Shanahan, F., and Collins, S. M. (2010). Pharmabiotic manipulation of the microbiota in gastrointestinal disorders, from rationale to reality. Gastroenterol. Clin. North Am. 39, 721-6. doi:10.1016/j.gtc.2010.08.006.

Sharon, G., Garg, N., Debelius, J., Knight, R., Dorrestein, P. C., and Mazmanian, S. K. (2014). Specialized metabolites from the microbiome in health and disease. Cell Metab. 20, 71930. doi:10.1016/j.cmet.2014.10.016.

Sherwin, E., Rea, K., Dinan, T. G., and Cryan, J. F. (2016). A gut (microbiome) feeling about the brain. Curr. Opin. Gastroenterol. 32, 96-102. doi:10.1097/MOG.0000000000000244.

Shigemori, S., and Shimosato, T. (2017). Applications of Genetically Modified Immunobiotics with High Immunoregulatory Capacity for Treatment of Inflammatory Bowel Diseases. Front. Immunol. 8, 22. doi:10.3389/fimmu.2017.00022.

Singh, P. K., Chopra, K., Kuhad, A., and Kaur, I. P. (2012). Role of Lactobacillus acidophilus loaded floating beads in chronic fatigue syndrome: behavioral and biochemical evidences. Neurogastroenterol. Motil. 24, 366-e170. doi:10.1111/j.13652982.2011.01861.x.

Slykerman, R. F., Hood, F., Wickens, K., Thompson, J. M. D., Barthow, C., Murphy, R., et al. (2017). Effect of Lactobacillus rhamnosus HNOO1 in Pregnancy on Postpartum Symptoms of Depression and Anxiety: A Randomised Double-blind Placebo-controlled Trial. EBioMedicine 24, 159-165. doi:10.1016/j.ebiom.2017.09.013.

Smith, C. J., Emge, J. R., Berzins, K., Lung, L., Khamishon, R., Shah, P., et al. (2014). Probiotics normalize the gut-brain-microbiota axis in immunodeficient mice. AJP Gastrointest. Liver Physiol. 307, G793-G802. doi:10.1152/ajpgi.00238.2014.

Spiller, R., and Garsed, K. (2009). Postinfectious irritable bowel syndrome. Gastroenterology 136, 1979-88. doi:10.1053/j.gastro.2009.02.074.

Steenbergen, L., Sellaro, R., van Hemert, S., Bosch, J. A., and Colzato, L. S. (2015). A randomized controlled trial to test the effect of multispecies probiotics on cognitive reactivity to sad mood. Brain. Behav. Immun. 48, 258-264. doi:10.1016/j.bbi.2015.04.003.

Stilling, R. M., Dinan, T. G., and Cryan, J. F. (2014). Microbial genes, brain \& behaviour epigenetic regulation of the gut-brain axis. Genes. Brain. Behav. 13, 69-86. doi:10.1111/gbb.12109.

Sullivan, A., Nord, C. E., and Evengård, B. (2009). Effect of supplement with lactic-acid producing bacteria on fatigue and physical activity in patients with chronic fatigue syndrome. Nutr. J. 8, 4. doi:10.1186/1475-2891-8-4.

Suo, H., Zhao, X., Qian, Y., Sun, P., Zhu, K., Li, J., et al. (2016). Lactobacillus fermentum Suo Attenuates $\mathrm{HCl} /$ Ethanol Induced Gastric Injury in Mice through Its Antioxidant Effects. Nutrients 8, 155. doi:10.3390/nu8030155.

Tack, J., and Drossman, D. A. (2017). What's new in Rome IV? Neurogastroenterol. Motil. doi:10.1111/nmo.13053.

Takeda, S., Igoshi, K., Tsend-Ayush, C., Oyunsuren, T., Sakata, R., Koga, Y., et al. (2017). Lactobacillus paracasei strain 06TCa19 suppresses inflammatory chemokine induced by 
Helicobacter pylori in human gastric epithelial cells. Hum. Cell. doi:10.1007/s13577-0170172-z.

Talley, N. J., Holtmann, G., and Walker, M. M. (2015). Therapeutic strategies for functional dyspepsia and irritable bowel syndrome based on pathophysiology. J. Gastroenterol. 50, 601-13. doi:10.1007/s00535-015-1076-x.

Taverniti, V., and Guglielmetti, S. (2011). The immunomodulatory properties of probiotic microorganisms beyond their viability (ghost probiotics: proposal of paraprobiotic concept). Genes Nutr. 6, 261-74. doi:10.1007/s12263-011-0218-x.

Theodorou, V., Belgnaoui, A. A., Agostini, S., and Eutamene, H. (2014). Effect of commensals and probiotics on visceral sensitivity and pain in irritable bowel syndrome. Gut Microbes 5, 430-629. doi:10.4161/gmic.29796.

Tiequn, B., Guanqun, C., and Shuo, Z. (2015). Therapeutic effects of Lactobacillus in treating irritable bowel syndrome: a meta-analysis. Intern. Med. 54, 243-9. doi:10.2169/internalmedicine.54.2710.

Tillisch, K., Labus, J., Kilpatrick, L., Jiang, Z., Stains, J., Ebrat, B., et al. (2013). Consumption of fermented milk product with probiotic modulates brain activity. Gastroenterology 144, 1394-401, 1401-4. doi:10.1053/j.gastro.2013.02.043.

Tillisch, K., Mayer, E. A., Gupta, A., Gill, Z., Brazeilles, R., Le Nevé, B., et al. (2017). Brain Structure and Response to Emotional Stimuli as Related to Gut Microbial Profiles in Healthy Women. Psychosom. Med. 79, 905-913. doi:10.1097/PSY.0000000000000493.

Upadhyay, N., and Moudgal, V. (2012). Probiotics: A review. J. Clin. Outcomes Manag. 19, 7684. doi:10.1016/S2221-1691(11)60174-3.

Vaghef-Mehrabany, E., Alipour, B., Homayouni-Rad, A., Sharif, S.-K., Asghari-Jafarabadi, M., and Zavvari, S. (2014). Probiotic supplementation improves inflammatory status in patients with rheumatoid arthritis. Nutrition 30, 430-435. doi:10.1016/j.nut.2013.09.007.

Vyas, U., and Ranganathan, N. (2012). Probiotics, prebiotics, and synbiotics: Gut and beyond. Gastroenterol. Res. Pract. 2012, 1-16. doi:10.1155/2012/872716.

Wagner, R. D., Pierson, C., Warner, T., Dohnalek, M., Hilty, M., and Balish, E. (2000). Probiotic effects of feeding heat-killed Lactobacillus acidophilus and Lactobacillus casei to Candida albicans-colonized immunodeficient mice. J. Food Prot. 63, 638-44. Available at: http://www.ncbi.nlm.nih.gov/pubmed/10826722.

Wall, R., Cryan, J. F., Ross, R. P., Fitzgerald, G. F., Dinan, T. G., and Stanton, C. (2014). Bacterial neuroactive compounds produced by psychobiotics. Adv. Exp. Med. Biol. 817, 221-39. doi:10.1007/978-1-4939-0897-4_10.

Wallace, T. C., Guarner, F., Madsen, K., Cabana, M. D., Gibson, G., Hentges, E., et al. (2011). Human gut microbiota and its relationship to health and disease. Nutr. Rev. 69, 392-403. doi:10.1111/j.1753-4887.2011.00402.x.

Wang, B., Mao, Y.-K., Diorio, C., Pasyk, M., Wu, R. Y., Bienenstock, J., et al. (2010a). Luminal administration ex vivo of a live Lactobacillus species moderates mouse jejunal motility within minutes. FASEB J. 24, 4078-88. doi:10.1096/fj.09-153841.

Wang, B., Mao, Y.-K., Diorio, C., Wang, L., Huizinga, J. D., Bienenstock, J., et al. (2010b). Lactobacillus reuteri ingestion and IK(Ca) channel blockade have similar effects on rat colon motility and myenteric neurones. Neurogastroenterol. Motil. 22, 98-107, e33. 
doi:10.1111/j.1365-2982.2009.01384.x.

Wang, F.-Y., Liu, J.-M., Luo, H.-H., Liu, A.-H., and Jiang, Y. (2015a). Potential protective effects of Clostridium butyricum on experimental gastric ulcers in mice. World J. Gastroenterol. 21, 8340-51. doi:10.3748/wjg.v21.i27.8340.

Wang, T., Hu, X., Liang, S., Li, W., Wu, X., Wang, L., et al. (2015b). Lactobacillus fermentum NS9 restores the antibiotic induced physiological and psychological abnormalities in rats. Benef. Microbes 6, 707-717. doi:10.3920/BM2014.0177.

Yang, H., Zhao, X., Tang, S., Huang, H., Zhao, X., Ning, Z., et al. (2016). Probiotics reduce psychological stress in patients before laryngeal cancer surgery. Asia. Pac. J. Clin. Oncol. 12, e92-e96. doi:10.1111/ajco.12120.

Yuan, F., Ni, H., Asche, C. V., Kim, M., Walayat, S., and Ren, J. (2017). Efficacy of Bifidobacterium infantis 35624 in patients with irritable bowel syndrome: a metaanalysis. Curr. Med. Res. Opin., 1-17. doi:10.1080/03007995.2017.1292230.

Zhang, M., Fan, X., Fang, B., Zhu, C., Zhu, J., and Ren, F. (2015). Effects of Lactobacillus salivarius Ren on cancer prevention and intestinal microbiota in 1, 2-dimethylhydrazineinduced rat model. J. Microbiol. 53, 398-405. doi:10.1007/s12275-015-5046-z. 